\title{
Sensitivity Analysis of Optimal Power Dispatch for All-Electric Ship
}

\author{
${ }^{1}$ GEORGE J. TSEKOURAS, ${ }^{2}$ FOTIOS D. KANELLOS, ${ }^{1}$ MICHALIS KONTOSOROS \\ ${ }^{1}$ Department of Electrical \& Electronics Engineering, ${ }^{2}$ School of Electrical \& Computer Engineering \\ ${ }^{1}$ Faculty of Engineering, University of West Attica, ${ }^{2}$ Technical University of Crete \\ 1250 Thivon Av., Aigaleo-Athens, GR12244, ${ }^{2}$ Aktotiri Campus, Chania, Crete, GR-73100 \\ ${ }^{1,2}$ GREECE
}

\begin{abstract}
Shipping industry is reforming and changing fast, as the International Maritime Organization (IMO) works towards air pollution prevention and ship-owners pursue more efficient operation of their ships. Formerly, propulsion and electric load dispatch in ship power system is implemented proportionally with respect to nominal power of prime movers and generators respectively. Additionally, integrated full electric propulsion, optimal real-time dispatch to ship generators and the integration of new systems, such as energy storage systems, shaft generators etc. could have gained a wider application. In this paper the optimal dispatch for ship power system based on Lagrange method is presented comparing the classic and all-electric ship design. The developed method is applied to an ten years old Ro-Ro (roll on / roll off) passenger ship and an analytical sensitivity analysis is occurred out with respect not only to technical characteristics of the ship, such as fuel kind, propulsion chain factors, but also voyage characteristics, such as ship speed, route length etc.
\end{abstract}

Key-Words: - All Electric Ship, optimization, power dispatch, ship energy efficiency

Received: October 5, 2020. Revised: March 7, 2021. Accepted: March 9, 2021.

Published: March 16, 2021.

\section{Introduction}

IMO is working towards the limitation of greenhouse gas (GHG) emissions by commercial ships [1]. Additionally, in 1973 the oil crisis, in 2008 the economic crisis and in 2020 the COVID crisis affected trade and transportation, creating a pressing need for efficiency improvement of ship energy systems.

Meanwhile, standard conventional practice in ships is to use a proportional distribution of electric power demand to their generators according to their nominal apparent powers [2-3]. However this does not take into consideration the varying efficiency of the engine at different load levels and the different cost of fuels used by ship engines [4]. It has been shown that the more electrified a ship is [5] the more efficient and greener it turns. All-electric ship (AES) concept offers many advantages such as increased safety, survivability, maneuverability, reduced machinery space, low noise, low operation and maintenance costs, low level of pollutant emissions, smooth and precise speed control. Additionally, Integrated Power System (IPS) has been regarded as the main design concept for ship power systems as it ensures an efficiently unified power supply and turns and generation system and enables integrated control of ship power system [6]. Moreover, it facilitates optimal economic dispatch
[7-8] that in contrast with shore power systems has limited application to ships. In [9] an optimal power management tool has been developed allowing: (a) the fuel consumption reduction in a wide range of variable speed operation, (b) the optimal commitment of ship engines for fuel and maintenance, (c) the application of energy storage systems etc. In [10] the ship power management system has been expanded taking into consideration several limitations and constraints regarding blackout prevention, power production consumption balance, generator frequent start/stop avoidance, and generator loading, ramp rate limitation ship speed, calls at intermediate ports, total travelled distance and greenhouse gas (GHG) emissions [1]. In both cases [9-10] the optimization problem was solved with the dynamic programming. A detailed review of the state of the art in AES is given in [11].

Despite the advantages which offered by AES people in shipping industry are still skeptical and prefer more classical solutions. In [4], [12] the economic load dispatch has been examined taking into account the classical power system with dieselelectric power units, as well as with the addition of shaft generators, based on Lagrange or dynamic method against the proportional one. In both cases 
the optimization process improves the respective results.

Additionally, last years the applications of alternative energy sources, especially photovoltaics [13-16], fuel cells [17], of energy storage systems [18-19], of voyage scheduling $[16,20]$ have also investigated. The respective results of a simplified Lagrange method are quite satisfactory [13-14]. In any case, the hybrid power systems focus on superior performance, emission reduction and fuel economy improvement $[17,21]$. It can also combine with dc distribution network and no-constant speed, optimum fuel consumption, ac-electric generator which is connected to the network through controlled rectifier [22] using new methods for realtime load management, such as multi-agent one [23], while the stochastic power load variability is taken into consideration [24-25].

In this paper, optimal power dispatch based on the Lagrange method using thermal units of a conventional ship power system and one with integrated full electric propulsion equipped is presented comparing with the proportional dispatch of the conventional ship (section 2). The comparison can be carried not only in general formation of system operation cost for different values of main propulsion load and electric load -methodology "A", but also in annual base of total operation cost for a specific ship route - methodology "B" (section 3). The proposed methodologies are applied to a typical Roll on / Roll off ship power system in sections 4 and 5 respectively for two types of configuration (conventional and AES). Sensitivity analyses for different parameters, i.e. ship speed for specific route, calls at intermediate ports, kind of fuel, etc., are occurred in order to detect cost affecting factors for the examination of ship power system configurations in respective sections. Finally, the respective conclusions are presented in section 6 .

\section{Ship Power System Operation}

\subsection{Configuration}

In Fig. 1, the single-line diagrams of the power system of a conventional ship and of an AES are shown. The most important difference is that the main propulsion power system and electric power system are separated in conventional ship configuration instead unified in AES one. Additionally, the thermal units are usually diesel engines, medium speed (300 to $900 \mathrm{rpm}$ ) and high speed (above $900 \mathrm{rpm}$ ) ones from few $\mathrm{kW}$ to $1 \div 3$ MW burning marine diesel oil (MDO) with lower net calorific value $42700 \mathrm{~kJ} / \mathrm{kg}$, used as electric generators prime movers and low speed ones (smaller than $300 \mathrm{rpm}$ ) from $1 \mathrm{MW}$ to $80 \mathrm{MW}$ burning intermediate diesel oil (IFO) with a maximum viscosity of 380 stokes and lower net calorific value $40000 \mathrm{~kJ} / \mathrm{kg}$, used as propulsion prime movers. More rarely gas turbines are used as prime movers in warships and passenger ships for maneuverability, high power density and low emissions reasons. Sometimes dual fuel diesel engines are fueled by either MDO, IFO or liquefied natural gas (LNG), as low speed engines burn MDO or IFO and gas turbines MDO or LNG. The last fuel is especially used in LNG carriers. Under these circumstances in classical ship configuration IFO or MDO thermal units are used as main propulsion prime movers and MDO or LNG thermal units are used as electric generator prime movers.

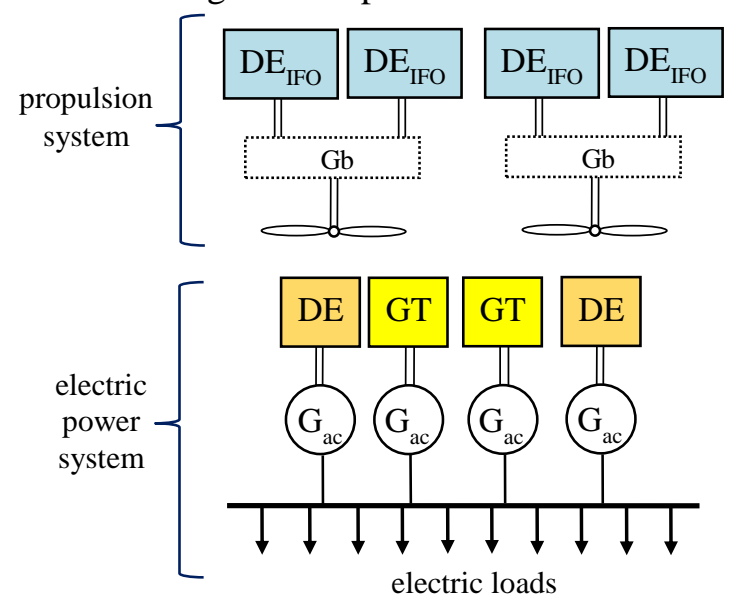

(a)

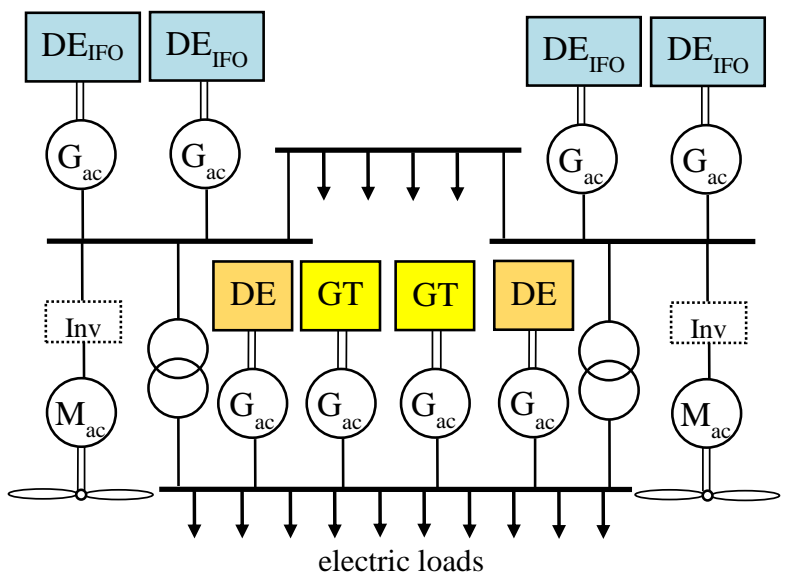

(b)

Fig. 1. Generic line diagram of (a) conventional, (b) all electric ship configuration (DE $\mathrm{DFO}_{\mathrm{IFO}}$ low speed diesel engine with intermediate diesel oil, DE: high speed diesel engine with marine diesel oil, $\mathrm{G}_{\mathrm{ac}}$ : ac generator, $\mathrm{Gb}$ : gearbox, GT: gas turbine, $\mathrm{M}_{\mathrm{ac}}$ : ac propulsion motor, Inv: inverter ac to ac).

It is noted that IFO use is limited in specific geographical areas, as in 2008 the revised Annex VI to Marpol 73/78 has required the sulphur content of 
any fuel (depending on crude oil origin and the refining process) on board not to exceed certain limits, as $3.50 \% \mathrm{~m} / \mathrm{m}$ on and after $1 / 1 / 2012,0.10 \%$ $\mathrm{m} / \mathrm{m}$ on and after $1 / 1 / 2015$ within an emission control area (ECA), including i.e. 200 nautical miles from the coasts of the USA, English Channel, North Sea, Baltic sea. Similar limitations have been placed by European Union, i.e. the EU directive 2005/33/EC extended the $1.5 \% \mathrm{~m} / \mathrm{m}$ limit to ferries operating to and from to any European Union port and the $0.1 \% \mathrm{~m} / \mathrm{m}$ limit to ships stayed at berth for more than 2 hours [21].

\subsection{Conventional ship power management}

In ship power systems the power dispatch is usually applied as follows: if the running generators $N_{E}^{\prime}$ are supplying ship electric load, next denoted by $P_{\text {el-load }}$, then the power $P_{i}$ by the $i$-th generator shall be produced:

$$
P_{i}=\frac{P_{\text {nom }, i}}{\sum_{i^{\prime} \in N_{E}^{\prime}} P_{n o m, i^{\prime}}} \cdot P_{e l-l o a d}
$$
also:

Power limitations of $i$-th electrical generator are

$$
P_{\text {min, } i} \leq P_{i} \leq P_{\text {max }, i}
$$

Where, $P_{\text {minTHi }}$ and $P_{\max T H i}$ are the respective minimum and maximum active power.

If load shedding is not intended, the number of essential running generators is specified according to $n-1$ criterion, which means that in case of the largest generator failure the ship load should be supplied sufficiently by the rest generators:

$$
\sum_{i \in N_{E}^{\prime}} P_{\max , i}-P_{e l-\text { load }} \geq \max _{i \in N_{E}^{\prime}}\left\{P_{\text {max }, i}\right\}
$$

The same process is applied for propulsion power system, except eq. (3), as in case of one prime mover loss the ship speed can be limited.

\subsection{Optimal economic dispatch in classical ship configuration}

The economically optimum operation of an electric power system for a specific system load level is known as economic dispatch [7-8]. Here, the power system includes $N_{E}$ thermal generating units connected to the same bus without transmission losses. $N_{E}^{\prime}$ thermal generating units are chosen to run during the $j$-th time interval denoted by $\Delta T_{j}$, that satisfy $n-1$ criterion according to eq. (3) and ensure the minimum possible operation cost. It is noted that the optimization period $T$ is divided into
$M$ intervals, $\Delta T_{\mathrm{j}}$, with $j=1,2, \ldots, M$. The ship load demand $P_{e l-\mathrm{j}}$ for each $\Delta T_{\mathrm{j}}$ is the respective average value:

$$
\int_{t_{j-1}}^{t_{j}} p_{e l}(t) \cdot d t=P_{e l-j} \cdot D T_{j}
$$

As the time interval $\Delta T_{\mathrm{j}}$ tends to zero, $P_{e l-\mathrm{j}}$ tends to the instantaneous demand load demand $p_{e l}(t)$. But for practical reasons the range of time interval $\Delta T_{\mathrm{j}}$ is between 15 and $60 \mathrm{~min}$.

Let the $i^{\text {th }}$ unit produces at the $j^{\text {th }}$ time interval active power $P_{\mathrm{TH} i, j}$ with respect to limitations of eq. (2). The respective fuel cost $F_{T H i}\left(P_{T H i, j}\right)$ is usually a polynomial of second or third order of $P_{\mathrm{TH} i, j}$ :

$$
F_{\mathrm{TH} i}\left(P_{\mathrm{TH} i, j}\right)=a_{i}+b_{i} \cdot P_{\mathrm{TH} i, j}+c_{i} \cdot P_{\mathrm{TH} i, j}^{2}+d_{i} \cdot P_{\mathrm{TH} i, j}^{3}
$$

Where $a_{i}, b_{i}, c_{i}, d_{i}$ are the coefficients of the polynomial function of $P_{\mathrm{TH} i, j}$ that approximates fuel cost.

The total fuel cost of the power system $F_{t o t, e l, j}$ over $\Delta T_{\mathrm{j}}$, is calculated as following:

$$
F_{\text {tot }, e l, j}=\sum_{i=1}^{\mathrm{N}_{E}^{\prime}} F_{\mathrm{TH} i}\left(P_{\mathrm{TH} i, j}\right)
$$

At each time interval $\Delta T_{j}$ the active power balance constraint should be applied:

$$
\sum_{i=1}^{N_{E}{ }^{\prime}} P_{\mathrm{TH} i, j}=P_{e l-j}
$$

The target of economic dispatch is to determine the power production levels of the thermal units that ensure active power balance constraint and minimize fuel cost $F_{t o t, e l, j}$. Assuming that fuel cost $F_{t o t, e l, j}$ in $j^{\text {th }}$ time interval is unrelated with its past values then total fuel cost over the optimization period $T$ is also minimized. The exploitation of the well-known Lagrange method can solve this problem based on the following equation:

$$
L_{\mathrm{tot}, j}=\sum_{i=1}^{N_{E}{ }^{\prime}} F_{\mathrm{TH} i}\left(P_{\mathrm{TH} i, j}\right)-\lambda_{j} \cdot\left(\sum_{i=1}^{N_{E}^{\prime}} P_{\mathrm{TH} i, j}-P_{e l-j}\right)
$$

The minimization requirements are adopted by setting the partial derivatives $\partial L_{\text {tot }, j} / \partial P_{\mathrm{TH} i, j}$ equal to 0 :

$$
\lambda_{j}=\frac{d F_{\mathrm{TH} i}\left(P_{\mathrm{TH} i, j}\right)}{d P_{\mathrm{TH} i, j}} \quad \forall i=1,2, \ldots, N_{E}^{\prime}
$$

According to (9) the load should be dispatched to the units in a way that incremental costs of the 
thermal units over time interval $\Delta T_{j}$ equal to the Lagrange coefficient, $\lambda_{j}$, which is known as system marginal cost (SMC). During time period $T$ if the supplied electric load varies, SMC will also vary.

If the fuel cost is a polynomial of third order then eq. (9) becomes:

$$
\lambda_{j}=b_{i}+2 \cdot c_{i} \cdot P_{\mathrm{TH} i, j}+3 \cdot d_{j} \cdot P_{\mathrm{TH} i, j}^{2}
$$

Using eq. (10), the generating level of the $i^{\text {th }}$ unit can be expressed by SMC $\lambda_{j}$ :

$$
P_{\mathrm{TH} i, j}=\left\{\begin{array}{cl}
\frac{\sqrt{c_{i}^{2}+3 \cdot\left(\lambda_{j}-b_{i}\right) \cdot d_{i}}-c_{i}}{3 \cdot d_{i}}, & d_{i} \neq 0 \\
\frac{\lambda_{j}-b_{i}}{2 \cdot c_{i}}, & d_{i}=0
\end{array}\right.
$$

Using Gauss-Seidel classic technique the determination of $\lambda_{j}$ for each time interval $\Delta T_{j}$ can be achieved. Next, the power production levels $P_{\mathrm{TH} i, j}$ are calculated and the power limitation constraints of eq.(2) are checked for each time interval $\Delta T_{j}$. If a violation occurs i.e. $P_{\mathrm{TH} 3, j}>P_{\max , 3}$, then the output active power is set to the violated limit, i.e. $P_{\mathrm{TH} 3, j}=$ $P_{\max , 3}$ and the load demand $P_{\mathrm{el}-j}$ is reduced to $P_{\text {el }-j}^{\prime}=$ $P_{\mathrm{el}-j}-P_{\mathrm{TH} 3, j}$. The optimization process is applied to the remaining units until it converges to a final solution that satisfies all constraints.

It is noted that, if the power system has $N_{E}$ electric generators, all possible combinations $\left(2^{N E}-1\right)$ will be implemented with respect to eq. (3) and the most inexpensive solution will be chosen. This is also applied in case of the proportional dispatch.

The same process can be applied for propulsion load $P_{p r}$ and the $N_{p r}{ }^{\prime}$ main prime movers thermal units, where the respective power production of the $k$-th unit $P_{\mathrm{ThPR} k, j}$, the propulsion marginal cost $\lambda_{\mathrm{PR} j}$ and the total fuel cost of the propulsion system $F_{t o t, p r, j}$ over $\Delta T_{\mathrm{j}}$ are calculated.

Finally, the total cost $F_{S}$ of the two systems for under study period (i.e. annual) is given by:

$$
F_{S}=\sum_{j=1}^{M}\left(F_{t o t, e l, j}+F_{t o t, p r, j}\right) \cdot \Delta T_{j}
$$

\subsection{Electric load}

Electric load $P_{\text {load_AES }}$ in AES has two additive components: the electric service load $P_{\text {servel }}$, which is common in classic configuration ship and AES, and the equivalent electric propulsion load $P_{\text {prop_el }}$. The electric service load includes:

- propulsion elements electric load, as high temperature cooling water pumps, fuel oil service pumps, lubricating oil pumps etc.,

- auxiliary systems, as fuel oil transfer pumps, fuel oil heaters, fuel oil separators etc.,

- hotel systems, as accommodation lighting and sockets, accommodation ventilation, airconditioning, hot water circulation pump, hot water heater, hydrophore system etc.,

- cargo systems, as cargo air-conditioning \& ventilation, reefer containers, electric supply / sockets for refrigerator trucks, etc.,

- hull machinery, steering gear, winches, cranes, catapults, bilge water pumps, ballast water pumps, fire-fighting system, general lightning, navigation systems, bow-thrusters etc [2].

Some electric loads have a periodic behavior, such as air-conditioning, which can depend from other parameters, i.e. humidity and temperature, or from operation conditions, i.e. at sea, maneuvering, in port / no loading, in port / loading, at anchor etc. Some other loads operate rarely, such as firefighting systems or evacuation winches. Most motors have nominal power from few $\mathrm{kW}$ to some decades $\mathrm{kW}$. However, bow thrusters are the biggest concentrated electric service loads, as their nominal power equal to $\mathrm{MW}$, and they operate during maneuvering giving the peak load for electric service load, as we can see in Fig. 2 for time subperiod $\left[t_{3}, t_{5}\right]$ and $\left[t_{9}, t_{11}\right]$. Specifically, in Fig. 2a the mean value of service electric power load is presented for a ship with daily route and in Fig $2 b$ the respective mean value ship speed indicatively. The trip duration is $\left[t_{4}, t_{10}\right]$, in port no loading subperiods are $\left[t_{1}, t_{2}\right] \&\left[t_{12}, t_{13}\right]$, in port loading subperiods are $\left[t_{2}, t_{3}\right] \&\left[t_{11}, t_{12}\right]$, manoeuvring subperiods are $\left[t_{3}, t_{4}\right] \&\left[t_{10}, t_{11}\right]$. It is noted that manoeuvring operation also exists at the beginning and ending of the trip $\left(\left[t_{4}, t_{5}\right] \&\left[t_{9}, t_{10}\right]\right.$ respectively).

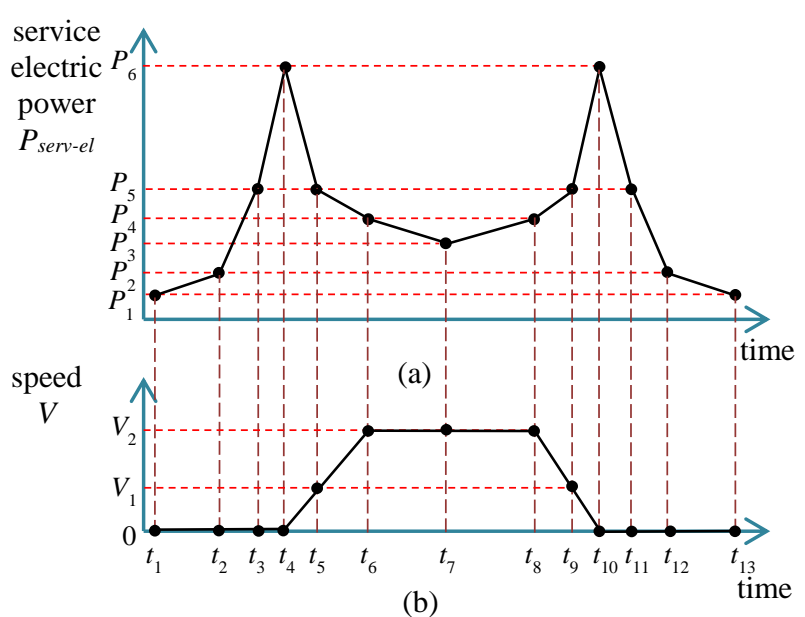

Fig. 2. Mean value of (a) service electric power load, (b) 
speed with respect to time for one daily route of a ship.

The propulsion load is given by the effective propulsion load $P_{\text {prop }}$ divided with the respective propulsion chain factor $n_{A E S}$, which includes the electric machines and components effects in efficiency:

$$
P_{\text {prop_el }}=P_{\text {prop }} / n_{\text {AES }}
$$

The effective propulsion / mechanical load $P_{\text {prop }}$ is analogous to ship speed $V$ in the third order and has the following form:

$$
P_{\text {prop }}=c_{P} \cdot V^{3}
$$

Where, coefficient $c_{p}$ depends on the ship hull geometry, loading conditions, water density, wake effect, etc. [2], [12].

In case of conventional ship configuration, the propulsion load is given by the effective propulsion load $P_{\text {prop }}$ divided with the respective propulsion chain factor $n_{\text {classic }}$, which includes the gear boxes, the axes, and the rest components effects in efficiency:

$$
P_{\text {prop_con }}=P_{\text {prop }} / n_{\text {classic }}
$$

In this study during the trip the ship performs a constant acceleration movement with acceleration $\gamma_{a c c}$ during sub-period $\left[t_{4}, t_{6}\right]$, a constant speed movement with speed $V$ during sub-period $\left[t_{6}, t_{8}\right]$ and a constant deceleration movement with deceleration $\gamma_{\text {dec }}$ during sub-period $\left[t_{8}, t_{10}\right]$ according to Fig. 2b. If the route length $\ell_{\text {route }}$, the calls of intermediate ports $n_{\text {inter }}$ with stop time duration $t_{\text {stop }}$ and the parameters $V, \gamma_{a c c}, \gamma_{d e c}$, are known, the acceleration time duration between two ports $t_{a c c}$ and the respective length $\ell_{a c c}$, the deceleration time duration between two ports $t_{d e c}$ and the respective length $\ell_{d e c}$, the constant speed mean time duration between two ports $t_{c o n \_s p}$ and the respective length $\ell_{c o n \_s p}$, as well as the total route time duration $t_{\text {route }}$ can be calculated as:

$$
\begin{gathered}
t_{a c c}=V / \gamma_{a c c} \\
t_{d e c}=V / \gamma_{d e c} \\
\ell_{a c c}=\frac{1}{2} \cdot \gamma_{a c c} \cdot t_{a c c}^{2} \\
\ell_{d e c}=\frac{1}{2} \cdot \gamma_{d e c} \cdot t_{d e c}^{2}
\end{gathered}
$$

$$
\begin{gathered}
\ell_{\text {con_sp }}=\ell_{\text {route }}-\left(n_{\text {inter }}+1\right) \cdot\left(\ell_{\text {acc }}+\ell_{\text {dec }}\right) \\
t_{\text {con_sp }}=\ell_{\text {con_sp }} / V \\
t_{\text {route }}=\left(n_{\text {inter }}+1\right) \cdot\left(t_{\text {acc }}+t_{\text {con_sp }}+t_{\text {dec }}\right)+n_{\text {inter }} \cdot t_{\text {stop }}
\end{gathered}
$$

\subsection{Optimal economic dispatch in AES configuration}

In case of AES optimal economic dispatch is based on eq. (1) to (11), with the only differentiation that electric load includes both components of §II.D. Practically, all prime movers (low speed and medium-high speed diesel engines of Fig.1) are coupled with electrical generators giving a unified power system.

\section{Proposed Methodologies for Financial Comparison}

The financial comparison between optimum economic dispatch and proportional one for a conventional ship (problem type "1") or optimum economic dispatch for AES and proportional one for the respective conventional ship (problem type " 2 ") can be realized with two methodologies.

In case of the methodology "A" the optimal economic dispatch for conventional ship or AES and the proportional dispatch for conventional ship are carried out for different values of electric service load in range $\left[P_{\text {el_min }}, P_{\text {el_max }}\right]$ with intermediate step $\mathrm{D} P_{e l}$ and of effective propulsion load in range $\left[P_{\text {prop_min }}, P_{\text {prop_max }}\right]$ with respective step D $P_{\text {prop. }}$. The hourly operation cost is estimated either separately for electric power system and propulsion system for problem type " 1 " or together for each combination $\left(P_{\text {servel } e l}, P_{\text {prop }}\right)$ for problem type "2". Finally, the respective minimum, maximum and indicative mean value operation cost are calculated under the condition that the probability density function for each load is uniform. Additionally, sensitivity analysis for different parameters, such as fuel oil type and AES propulsion chain factor, can be carried out.

In case of the methodology "B" both problem types are carried out for a specific ship route taking into account the respective chronological load curve of electric service load and of effective propulsion load during operation and no operation of the ship. The annual operation cost is estimated by eq. (12) and sensitivity analysis is carried out not only for typical ship characteristics, such as fuel oil type and AES propulsion chain factor, but also for trip characteristics, such as route length, route speed, 
intermediate ports number etc., for a specific transport work.

\section{Application of the Proposed Methodology "A"}

\subsection{Ship data}

The developed methodology is applied to a typical Ro-Ro ship, with the following characteristics:

- 2320 passengers, 130 crew, 660 vehicles, 31.6 knots nominal speed,

- deadweight $=5500 \mathrm{tn}$,

- gross deadweight $=37000 \mathrm{tn}$,

- 2 propellers x $33600 \mathrm{~kW}$,

- 2 forward bow thrusters $x 1200 \mathrm{~kW}$,

- 2 aft bow thrusters x $1000 \mathrm{~kW}$,

- 6 high speed marine diesel electric generators $x$ $2000 \mathrm{~kW}$, with the purpose of supplying the electric service load,

- 4 low speed main diesel machines (or diesel electric machines for AES) x $16800 \mathrm{~kW}$, which can use intermediate diesel fuel or marine diesel fuel, with the purpose of supplying the main propulsion load.

In case of AES the respective propulsion chain factor $n_{A E S}$, from electric generator to propeller, is equal to 0.92 , while in case of conventional ship the respective chain factor $n_{\text {classic }}$, from prime mover to propeller, is equal to 0.97 . Additionally, the low speed diesel engine can burn IFO with a maximum viscosity of 380 centistokes (IFO 380), or MFO with typical cost 408 m.u./kg $\kappa \alpha 1600$ m.u/kg [27] respectively. On the contrary the high speed diesel engines consume only MFO. The respective fuel cost are increased by $2.5 \%$ for low speed engines and $1.3 \%$ for high speed ones respectively because of maintenance operation cost (cylinder and circulation lubrication oil consumption) [28].

In Table 1 the fuel cost function parameters (eq. (5)), kind of fuel oil and technical minimum / maximum power productions (eq. (2)) are used for the 6 high-speed diesel electric generators and the 4 low-speed diesel electric generators / prime movers. In case of the methodology " $A$ " the values of electric service load are varied from $200 \mathrm{~kW}$ to $10000 \mathrm{~kW}$ with step of $200 \mathrm{~kW}$ and of effective propulsion load from $0 \mathrm{~kW}$ to $68000 \mathrm{~kW}$ with step of $400 \mathrm{~kW}$.

\subsection{Problem type "1" - Basic Scenario}

In all cases of comparison between optimum economic dispatch and proportional one for a conventional ship configuration (service electric load, propulsion system using IFO or MFO) there is not significant improvement of hourly operation cost either in percentage reduction cost, or in monetary unit, as it is presented in Table 2 .

Table 1: Fuel cost function parameters \& technical $\mathrm{min} / \mathrm{max}$ power production for generators / prime movers of ship power system

\begin{tabular}{cccccccc}
\hline \hline No. & $P_{\text {nom }}$ & Fuel oil & $a_{i}$ & $b_{i}$ & $c_{i}$ & $P_{\min }$ & $P_{\max }$ \\
- & $\mathrm{kW}$ & - & m.u. /h & $\begin{array}{c}10^{-2} \mathrm{~m} . \mathrm{u} . / \\
(\mathrm{kW} \cdot \mathrm{h})\end{array}$ & $\begin{array}{c}10^{-6} \mathrm{~m} . \mathrm{u} . \\
/\left(\mathrm{kW}^{2} \cdot \mathrm{h}\right)\end{array}$ & $\mathrm{kW}$ & $\mathrm{kW}$ \\
\hline 1 & 2000 & MFO & 13.681 & 3.7536 & 5.0330 & 300 & 2100 \\
2 & 2000 & MFO & 13.689 & 3.7339 & 5.1440 & 300 & 2100 \\
3 & 2000 & MFO & 13.649 & 3.8216 & 5.1561 & 300 & 2100 \\
4 & 2000 & MFO & 13.673 & 3.8064 & 5.2319 & 300 & 2100 \\
5 & 2000 & MFO & 13.691 & 3.7458 & 5.3836 & 300 & 2100 \\
6 & 2000 & MFO & 13.709 & 3.7609 & 5.4594 & 300 & 2100 \\
7 & 16800 & MFO & 65.664 & 4.3459 & 0.78107 & 3360 & 17640 \\
8 & 16800 & MFO & 74.338 & 4.2805 & 0.76949 & 3360 & 17640 \\
9 & 16800 & MFO & 66.726 & 4.2968 & 0.77372 & 3360 & 17640 \\
10 & 16800 & MFO & 69.759 & 4.3148 & 0.77802 & 3360 & 17640 \\
-7 & 16800 & IFO 380 & 46.190 & 3.0570 & 0.54943 & 3360 & 17640 \\
8 & 16800 & IFO 380 & 52.292 & 3.0110 & 0.54128 & 3360 & 17640 \\
9 & 16800 & IFO 380 & 46.937 & 3.0224 & 0.54426 & 3360 & 17640 \\
10 & 16800 & IFO 380 & 49.071 & 3.0352 & 0.54728 & 3360 & 17640 \\
\hline \hline
\end{tabular}

Table 2: Reduction cost from optimal economic dispatch instead of proportional dispatch in classic configuration ship (per: Percentage reduction cost in \%, sav_c: reduction cost in m.u./h with respect to proportional hourly operation cost, $o p \_c$ in $\mathrm{m} . \mathrm{u} . / \mathrm{h}$ for respective load $P_{l}$ in $\left.\mathrm{kW}\right)$

\begin{tabular}{|c|c|c|c|c|}
\hline Case & Variables & $\begin{array}{c}\text { Service } \\
\text { electric load }\end{array}$ & $\begin{array}{c}\text { Propulsion } \\
\text { load /IFO }\end{array}$ & $\begin{array}{l}\text { Propulsion } \\
\text { load /MDO }\end{array}$ \\
\hline \multirow{4}{*}{$\begin{array}{l}\text { Minimum } \\
\text { percentage } \\
\text { reduction } \\
\text { cost }\end{array}$} & per & 0.0000 & 0.0000 & 0.0000 \\
\hline & $s a v_{-} c$ & 0.000 & 0.000 & 0.000 \\
\hline & $o p \_c$ & 21.362 & 0.000 & 0.000 \\
\hline & $P_{l}$ & 200 & 0 & 0 \\
\hline \multirow{4}{*}{$\begin{array}{l}\text { Average } \\
\text { percentage } \\
\text { reduction } \\
\text { cost }\end{array}$} & per & 0.0101 & 0.0043 & 0.0043 \\
\hline & $s a v \_c$ & 0.040 & 0.073 & 0.104 \\
\hline & $o p \_c$ & 278.607 & 1447.643 & 2057.981 \\
\hline & $P_{l}$ & 5100 & 34000 & 34000 \\
\hline \multirow{4}{*}{$\begin{array}{l}\text { Maximum } \\
\text { percentage } \\
\text { reduction } \\
\text { cost }\end{array}$} & per & 0.0221 & 0.0075 & 0.0075 \\
\hline & $s a v \_c$ & 0.089 & 0.097 & 0.183 \\
\hline & $o p \_c$ & 404.104 & 1290.732 & 1834.915 \\
\hline & $P_{l}$ & 7400 & 30800 & 30800 \\
\hline \multirow{4}{*}{$\begin{array}{l}\text { Maximum } \\
\text { reduction } \\
\text { cost }\end{array}$} & per & 0.0193 & 0.0047 & 0.0047 \\
\hline & $s a v \_c$ & 0.095 & 0.139 & 0.198 \\
\hline & $o p \_c$ & 491.910 & 2949.209 & 4192.618 \\
\hline & $P_{l}$ & 9000 & 67200 & 67200 \\
\hline
\end{tabular}

\subsection{Problem type "1" - Sensitivity analysis}

The change of fuel oil kind from MDO to IFO 380 for propulsion system does not modify the percentage reduction cost in all propulsion loads, but only the monetary unit cost, where the use of IFO 380 is more desirable. However, there is the problem, if the IFO use is legal according to vessel route. Furthermore, the change of fuel oil cost does not modify the percentage reduction cost, because the electric power system and propulsion system operate independently and the fuel cost functions of generators / prime movers change proportionally. The infinitesimal improvement by economic power dispatch application instead of proportional dispatch is due to the almost identical economic and technical characteristics of prime movers for each 
system, which lead on to similar results between two dispatch kinds.

\subsection{Problem type "2" - Basic Scenario}

Here, optimum economic dispatch for AES and proportional one for conventional ship configuration are carried out for all combinations of electric power load and effective propulsion load. In Fig.3 the percentage reduction cost is presented for different loads $\left(P_{\text {serv_el }}, P_{\text {prop }}\right)$, where low speed diesel engines use IFO 380 and high speed ones MDO. It is obvious that AES has a significant advantage against conventional one for medium to high service electric load and for low to medium effective propulsion load, because the main prime movers, which were used for propulsion system initially, operate as generators supplying electric service load in a more inexpensive way. This conclusion is more obvious in Fig.4, where the light colored area is proposed using AES with optimal economic dispatch, as cost reduction cost is positive.

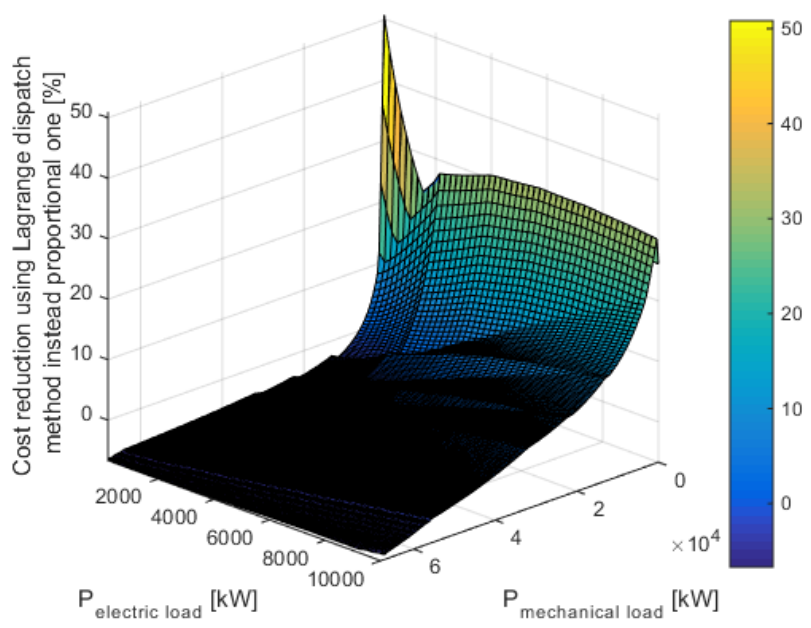

Fig. 3. Percentage reduction cost using Lagrange dispatch in AES instead of proportional dispatch in similar classic ship burning different fuel oil (low-speed diesel engines: IFO 380, high speed ones: MDO) with $n_{A E S}=0.92$, $n_{\text {classic }}=0.97$ with respect to electric service load and effective propulsion load.

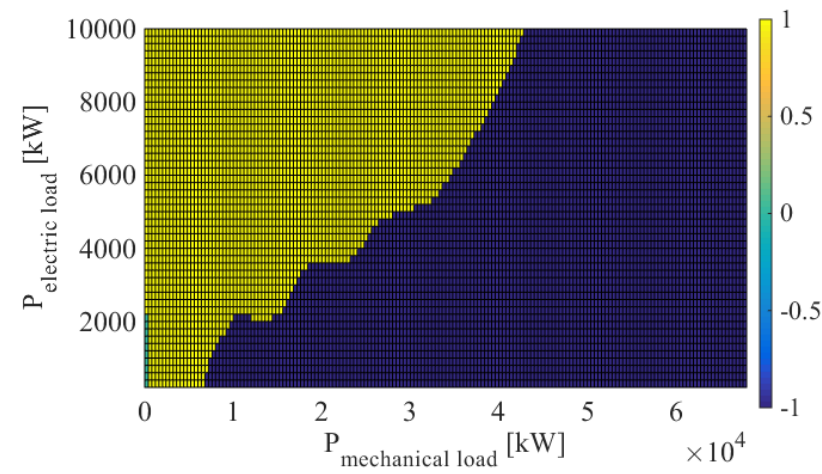

Fig. 4. Proposed light colored area using Lagrange dispatch in AES instead of proportional dispatch in similar classic ship burning different fuel oil (low-speed diesel engines: IFO 380, high speed ones: MDO) with
$n_{A E S}=0.92, \quad n_{\text {classic }}=0.97$ with respect to electric service load and effective propulsion load.

The percentage reduction cost varies from $6.68 \%$ to $50.83 \%$ with indicative mean value $0.95 \%$, as it is presented in Table 3.

Table 3: Reduction cost from optimal economic dispatch in AES instead of proportional dispatch in classic configuration ship (per: Percentage reduction cost in \%, $s a v_{c} c$ : reduction cost in m.u./h with respect to proportional hourly operation cost, $o p \_c$ in m.u./h for respective load $P_{l}$ in $\mathrm{kW}$ )

\begin{tabular}{|c|c|c|c|}
\hline Case & Variables & $\begin{array}{c}\text { Use of IFO } 380 \\
\& \text { MDO }\end{array}$ & $\begin{array}{l}\text { Use only of } \\
\text { MDO }\end{array}$ \\
\hline \multirow{4}{*}{$\begin{array}{c}\text { Minimum } \\
\text { percentage } \\
\text { reduction } \\
\text { cost }\end{array}$} & per & -6.6783 & -4.8747 \\
\hline & $s a v_{-} c$ & -204.075 & -231.013 \\
\hline & $o p \_c$ & 3055.792 & 4738.991 \\
\hline & $P_{\text {prop, }}, P_{\text {servel }}$ & 1200,68000 & 10000,67200 \\
\hline \multirow{4}{*}{$\begin{array}{l}\text { Minimum } \\
\text { reduction } \\
\text { cost }\end{array}$} & per & -6.0882 & -4.8747 \\
\hline & $s a v \_c$ & -212.644 & -231.013 \\
\hline & $o p \_c$ & 3492.698 & 4738.991 \\
\hline & $P_{\text {prop }}, P_{\text {servel }}$ & 9200,68000 & 10000,67200 \\
\hline \multirow{4}{*}{$\begin{array}{l}\text { Average } \\
\text { percentage } \\
\text { reduction } \\
\text { cost }\end{array}$} & per & 0.9468 & -2.4454 \\
\hline & $s a v \_c$ & 183.677 & -81.603 \\
\hline & $o p \_c$ & 1726.250 & 2336.588 \\
\hline & $P_{\text {prop },}, P_{\text {servel }}$ & 5100,34000 & 5100,34000 \\
\hline \multirow{4}{*}{$\begin{array}{l}\text { Maximum } \\
\text { percentage } \\
\text { reduction } \\
\text { cost }\end{array}$} & per & 50.8254 & 62.4444 \\
\hline & $s a v_{-} c$ & 40.788 & 65.617 \\
\hline & $o p \_c$ & 80.252 & 105.081 \\
\hline & $P_{\text {prop }}, P_{\text {servel }}$ & 200,400 & 200,400 \\
\hline \multirow{4}{*}{$\begin{array}{c}\text { Maximum } \\
\text { redution } \\
\text { cost }\end{array}$} & per & 28.8573 & 62.4444 \\
\hline & $s a v_{-} c$ & 183.677 & 65.617 \\
\hline & $o p \_c$ & 605.263 & 105.081 \\
\hline & $P_{\text {prop }}, P_{\text {servel }}$ & 10000,800 & 200,400 \\
\hline
\end{tabular}

In Fig. 5 the percentage reduction cost is presented for different loads $\left(P_{\text {servelel }}, P_{\text {prop }}\right)$, where both low and high speed diesel engines use MDO for environmental / legislation reasons. It is obvious that AES has a limited advantage against conventional one for very low effective propulsion load. This conclusion is also obvious in Fig. 6. This happens, because the main prime movers, which were used for propulsion system initially, do not use the cheaper IFO 380, but MDO, which means that their inexpensive operation is based on the slightly better efficiency than the classical high speed diesel electric generators. The last one is not in effect for every load combination. The percentage reduction cost varies from $-4.88 \%$ to $62.44 \%$ with indicative mean value $-2.45 \%$, as it is presented in Table 3 .

\subsection{Problem type "2" - Sensitivity analysis}

The change of fuel oil kind from MDO to IFO 380 for main prime movers, which were used for propulsion system initially, modifies the percentage reduction cost and the monetary unit cost significantly, as it can be noticed by the comparison of Fig. 3, 4 to Fig. 5, 6 and by respective numerical results in Table 3 . The use of IFO $380 \&$ MDO leads on to positive indicative mean value 
percentage reduction cost instead of the negative one of only use of MDO. Additionally, the minimum, the maximum and the mean value reduction operation cost of IFO 380 \& MDO are bigger than the respective ones of only use of MDO.

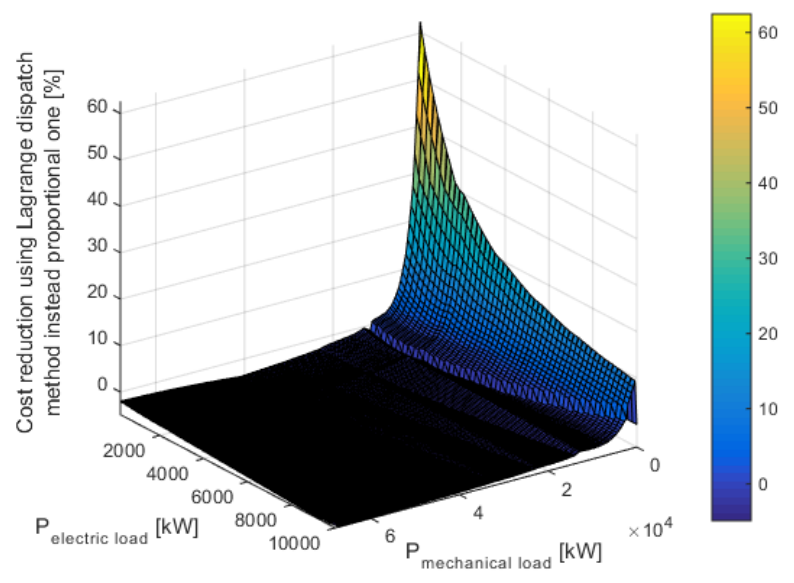

Fig. 5. Percentage reduction cost using Lagrange dispatch in AES instead of proportional dispatch in similar classic ship burning same fuel oil for all engines (MDO) with $n_{A E S}=0.92, \quad n_{\text {classic }}=0.97$ with respect to electric service load and effective propulsion load.

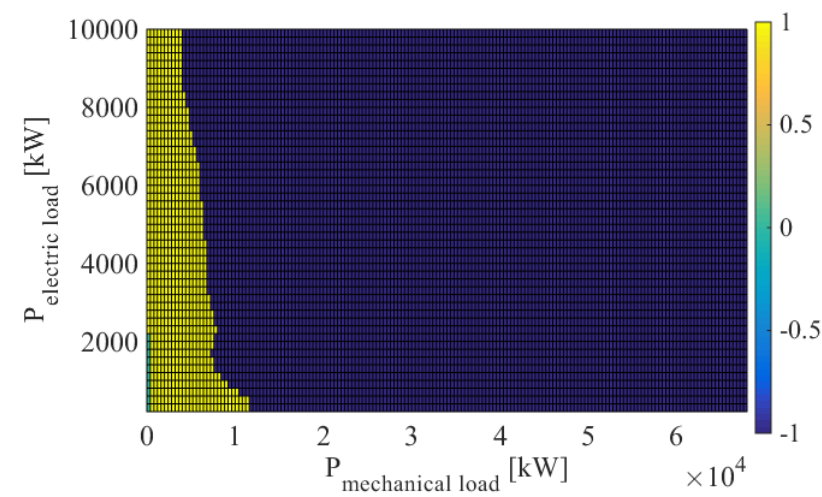

Fig. 6. Proposed light colored area using Lagrange dispatch in AES instead of proportional dispatch in similar classic ship burning same fuel oil for all engines (MDO) with $n_{A E S}=0.92, \quad n_{\text {classic }}=0.97$ with respect to electric service load and effective propulsion load.

Furthermore, the change of fuel oil cost does not modify the percentage reduction cost in case of use of MDO only, because the fuel cost functions of generators / prime movers change proportionally. On the contrary, in case of use IFO $380 \&$ MDO the ratio between the MDO cost and IFO 380 one influences the percentage reduction cost, where the ratio increment improves the respective mean value from $-3.3 \%$ to $5.9 \%$, as it can be seen in Fig. 7, while the light proposed area of Fig. 4, 6 are also expanded. The neutral situation happens for $135 \%$ ratio approximately, while the minimum percentage reduction cost varies from $-5 \%$ to $-38 \%$ and the maximum one from $42 \%$ to $60 \%$. It is noted that a nonlinear behavior is presented in range of ratio $175 \%-180 \%$, while the ratio value is $142 \%$ approximately for the basic scenario [27], where the percentage reduction cost is slightly positive.

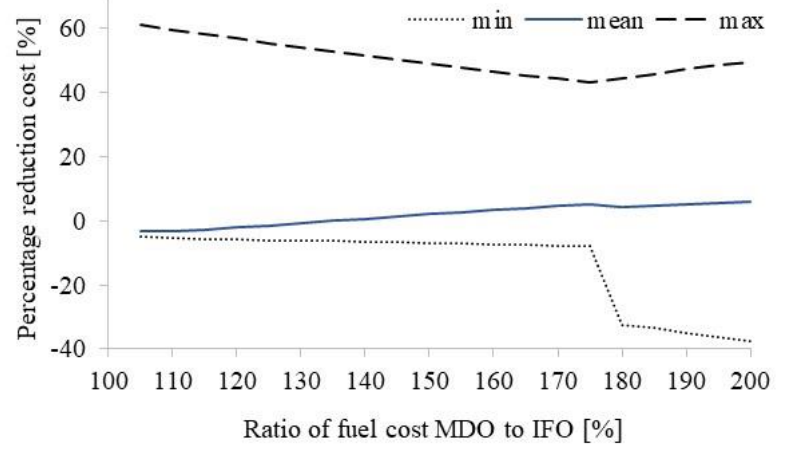

Fig. 7. Percentage reduction cost using Lagrange dispatch in AES instead of proportional dispatch in similar classic ship burning different fuel oil (low-speed diesel engine: IFO 380, high speed diesel engine: MDO), with respect to ratio of fuel cost MDO to IFO 380, for all combinations of electric service load and effective propulsion load, with $n_{A E S}=0.92, n_{\text {classic }}=0.97$.

The AES propulsion chain factor $n_{A E S}$ has the most significant role, because it will be improved during next years, while the respective conventional chain factor $n_{\text {classic }}$ has reached the maximum practical value of 0.97 . The increase of $n_{A E S}$ leads on to the expansion of the light colored area expansion, where AES Lagrange dispatch is superior to the proportional dispatch of conventional ship, in both cases of fuel use (IFO $380 \&$ MDO and MDO only). In case of use IFO $380 \&$ MDO the limit of lighted plotted area is moved from left-up to right-down, as it can be seen by the comparison of Fig. 4, 8, 9. While in case of use MDO only the limit of lighted plotted area is moved from down to up non-nonuniformly, as it can be seen by the comparison of Fig. 6, 10, 11.

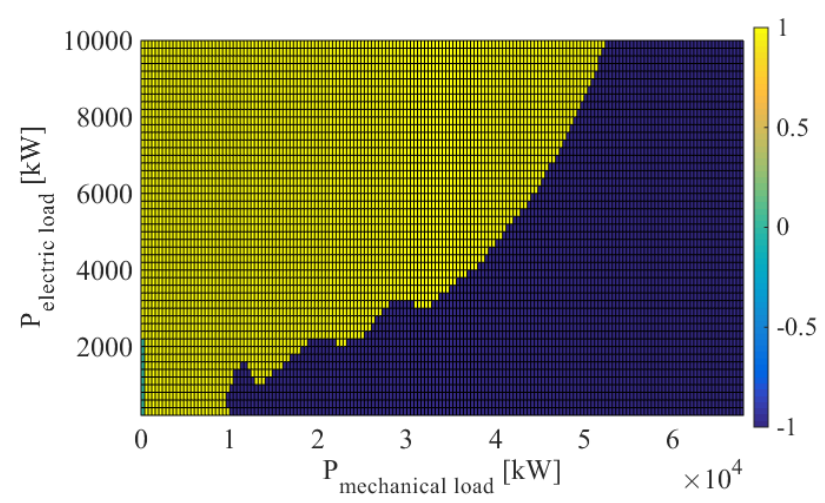

Fig. 8. Proposed light colored area using Lagrange dispatch in AES instead of proportional dispatch in similar classic ship burning different fuel oil (low-speed diesel engine: IFO 380, high speed diesel engine: MDO) 
with $n_{A E S}=0.94, n_{\text {classic }}=0.97$.

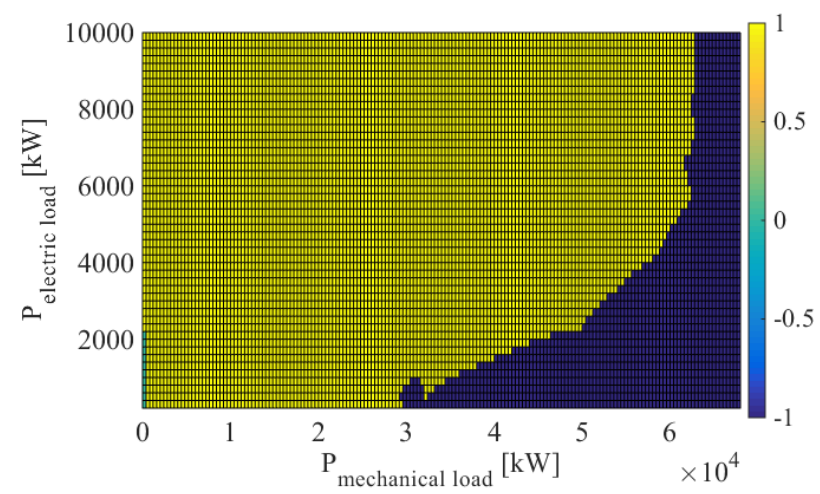

Fig. 9. Proposed light colored area using Lagrange dispatch in AES instead of proportional dispatch in similar classic ship burning different fuel oil (low-speed diesel engine: IFO 380, high speed diesel engine: MDO) with $n_{A E S}=0.96, n_{\text {classic }}=0.97$.

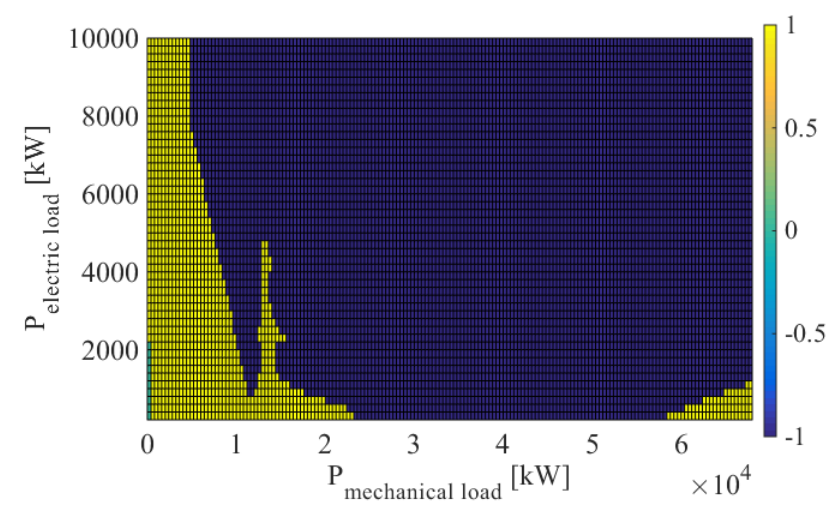

Fig. 10. Proposed light colored area using Lagrange dispatch in AES instead of proportional dispatch in similar classic ship burning same fuel oil for all engines (MDO) with $n_{A E S}=0.94, n_{\text {classic }}=0.97$.

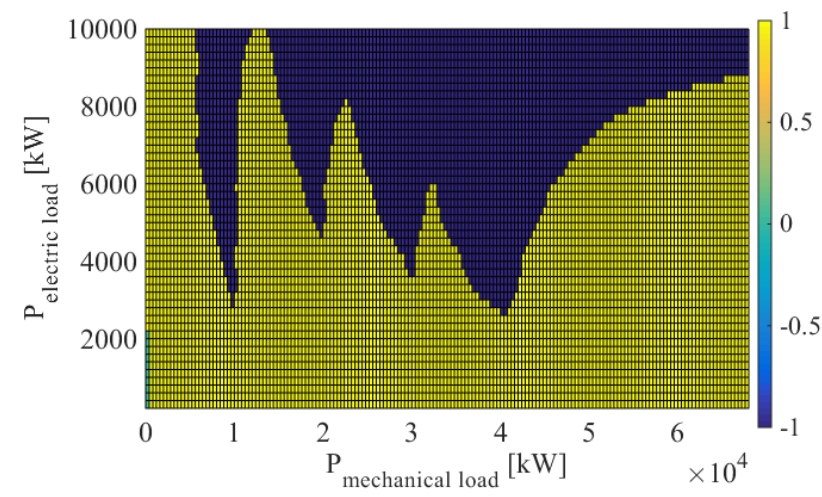

Fig. 11. Proposed light colored area using Lagrange dispatch in AES instead of proportional dispatch in similar classic ship burning same fuel oil for all engines (MDO) with $n_{A E S}=0.96, n_{\text {classic }}=0.97$.

In all cases, the maximum speed, the time duration and the route length of the typical ship trip, the annual days' operation, the life cycle etc. play a key role for the AES economic viability. If the combinations of electric service load and of effective propulsion load with the light colored area in Fig 4, 6 obtain, it will be possible for AES configuration to be more profitable than conventional one.

\section{Application of the Proposed Methodology "B"}

\subsection{Ship data}

Except ship data in $\S 4.1$ additional data are given for the typical route:

- speed with respect to Fig.2b, where $V_{l}=10$ knots, maximum trip speed $V_{2}=V=22$ knots for basic scenario, 16.0, 16.25, ..., 31.5 knots for sensitivity analysis,

- route length $\ell_{\text {route }}=175$ nautical miles for basic scenario, 50, 75, .. 300 for sensitivity analysis,

- acceleration $\gamma_{a c c}=$ deceleration $\gamma_{d e c}=40 \mathrm{knots} / \mathrm{h}$,

- intermediate ports $n_{\text {inter }}=0$ for basic scenario, $1 \ldots 4$ for sensitivity analysis,

- mean value service electric power load with respect to Fig.2a, where $P_{1}=200 \mathrm{~kW}, P_{2}=3000$ $\mathrm{kW}, P_{3}=1500 \mathrm{~kW}, P_{4}=2000 \mathrm{~kW}, P_{5}=4000$ $\mathrm{kW}, P_{6}=6000 \mathrm{~kW}$,

- time parameters for daily route of Fig. 2, where $t_{1}=0$, departure time from the $1^{\text {st }}$ port, $t_{4}=3.00, t_{2}=$ $t_{4}-2 \mathrm{~min}, t_{3}=t_{4}-1 \mathrm{~min}, t_{5}=t_{4}+15 \mathrm{~min}=t_{4}+V_{1} / \gamma_{a c c}$, $t_{6}=t_{4}+t_{a c c}, t_{7}=t_{6}+t_{c o n_{-} s p} / 2, \quad t_{8}=t_{6}+t_{c o n \_s p}$, arrival time to the $2^{\text {nd }}$ port $t_{10}=t_{8}+t_{d e c}, t_{9}=t_{10}-15 \mathrm{~min}=t_{10^{-}}$ $V_{1} / \gamma_{\text {dec }}, t_{11}=t_{10}+1 \mathrm{~min}, t_{12}=t_{10}+2 \mathrm{~min}, t_{13}=24.00$ for basic scenario without no intermediate port, while in case of $n_{\text {inter }}$ calls at intermediate ports $\ell_{\text {route }}$ is divided by $n_{\text {inter }}$, the ship remains in each intermediate port for $t_{\text {stop }}=15 \mathrm{~min}$ and the respective time points are modified properly,

- mean value service electric power load $P_{1}=200$ $\mathrm{kW}$, effective propulsion load $0 \mathrm{~kW}$ for no operation days for every minute.

Indicatively, in Fig. 12, 13, 14 the speed, the effective propulsion load and service electric load for a typical daily route of $175 \mathrm{n}$. miles with 22 knots are presented respectively with no and 4 calls at intermediate ports.

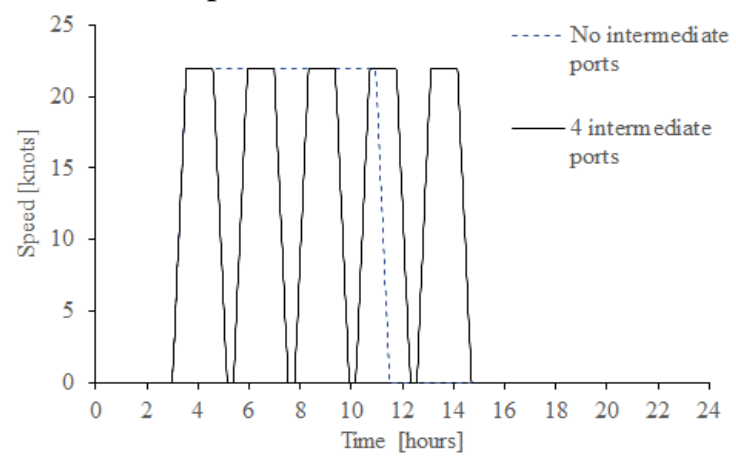

Fig. 12. Ship speed with respect to time for a typical operation day with $\ell_{\text {route }}=175$ n.miles, $V=22$ knots, 
$n_{\text {AES }}=0.92, n_{\text {classic }}=0.97,0 \& 4$ calls at intermediate ports.

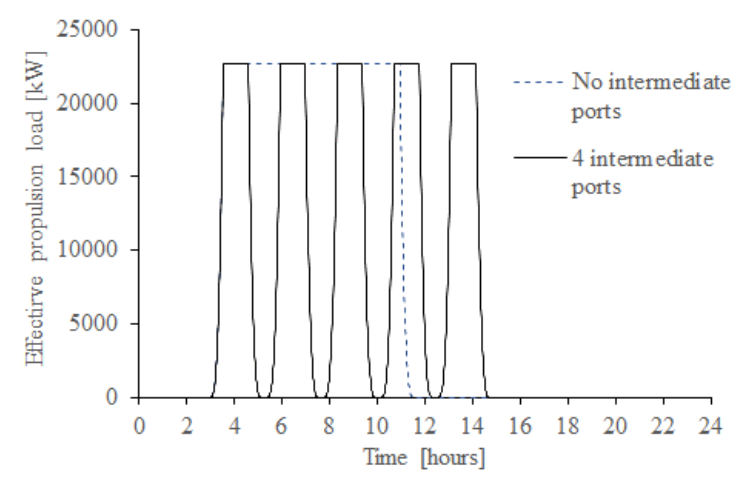

Fig. 13. Effective propulsion load with respect to time for a typical operation day with $\ell_{\text {route }}=175$ n.miles, $V=22$ knots, $n_{A E S}=0.92, n_{\text {classic }}=0.97,0 \& 4$ calls at intermediate ports.

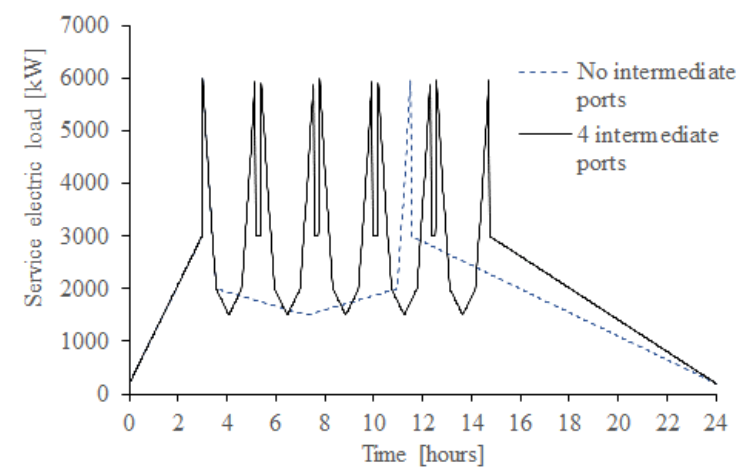

Fig. 14. Service electric load with respect to time for a typical operation day with $\ell_{\text {route }}=175$ n.miles, $V=22$ knots, $n_{A E S}=0.92, n_{\text {classic }}=0.97,0 \& 4$ calls at intermediate ports.

\subsection{Problem type "1" - Basic Scenario}

In order to compare the optimum economic dispatch and proportional one for the conventional ship configuration in a specific route (basic scenario) the annual duration effective propulsion load curve is formed in Fig. 15 including operation and nooperation days, as well as the respective electric service load is presented in Fig. 16. Next, the optimal economic dispatch is carried out in both cases (propulsion system using IFO or MFO) and the respective system marginal costs (SMCs) are presented in Fig. 17, as well as the generating levels of the generators and of the prime movers are also shown in Fig. 18 and 19 respectively.

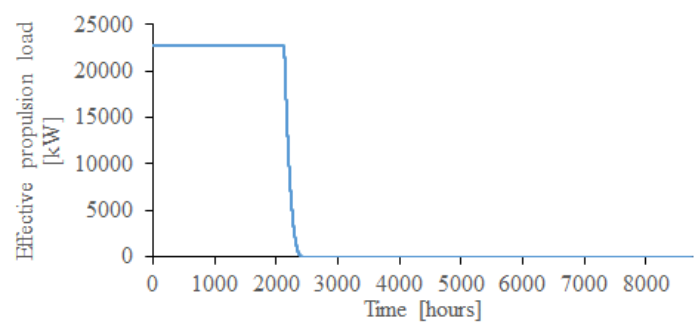

Fig. 15. Annual duration curve of effective propulsion load, where a typical operation day has $\ell_{\text {route }}=175$ n.miles, $V=22$ knots, $n_{A E S}=0.92, \quad n_{\text {classic }}=0.97 \& 0$ calls at intermediate ports.

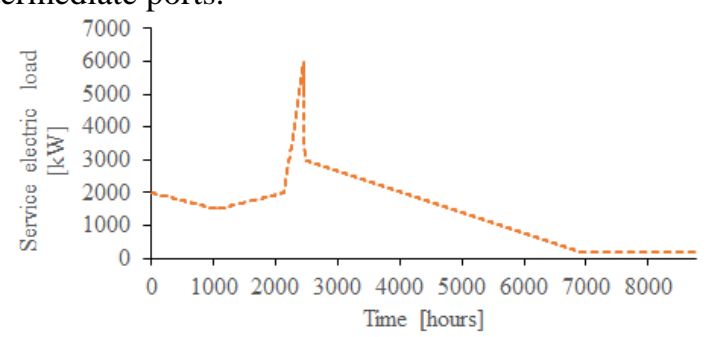

Fig. 16. Annual service electric load curve with respect to annual duration curve of effective propulsion load, where a typical operation day has $\ell_{\text {route }}=175$ n.miles, $V=22$ knots, $n_{A E S}=0.92, n_{\text {classic }}=0.97 \& 0$ calls at intermediate ports.

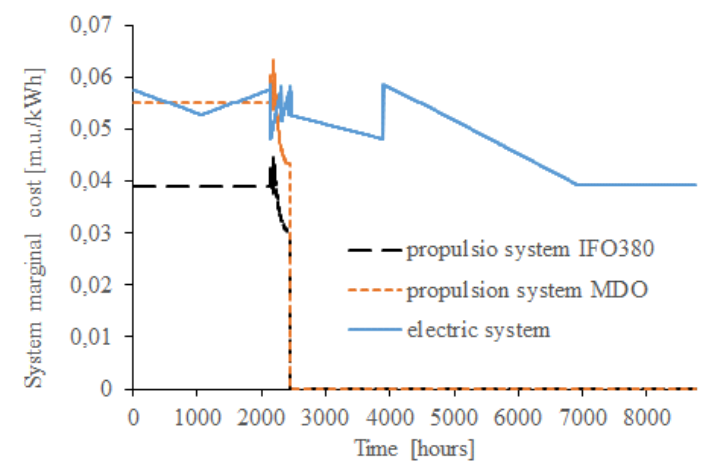

Fig. 17. System marginal cost curve for electric power system, for propulsion system using IFO 380, for propulsion system using MDO, with respect to annual duration curve of effective propulsion load, where a typical operation day has $\ell_{\text {route }}=175$ n.miles, $V=22$ knots, $n_{A E S}=0.92, n_{\text {classic }}=0.97 \& 0$ calls at intermediate ports.

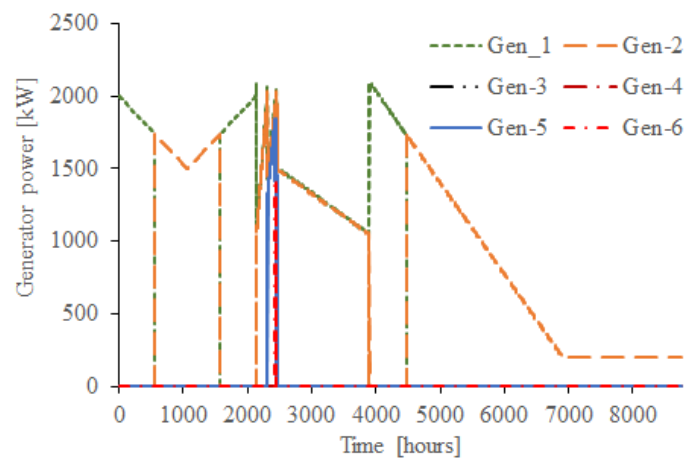

Fig. 18. Generating levels of the generators for electric power system with respect to annual duration curve of effective propulsion load, where a typical operation day has $\ell_{\text {route }}=175$ n.miles, $V=22$ knots, $n_{\text {AES }}=0.92, n_{\text {classic }}=0.97$ $\& 0$ calls at intermediate ports.

The respective results for the proportional dispatch are quite similar, because the economic and technical characteristics of prime movers for each system are almost identical. In case of using IFO 380 for propulsion system the annual operation cost is equal to $2,821,417.237 \mathrm{~m} . \mathrm{u}$. for proportional dispatch, while the cost reduction for optimal dispatch is 96.905 m.u., otherwise $0.00343 \%$. In case of using MDO for propulsion system the 
respective results are 3,712,109.644 m.u., 134.466 m.u., otherwise $0.00365 \%$ respectively. In both cases the improvement is practically null.

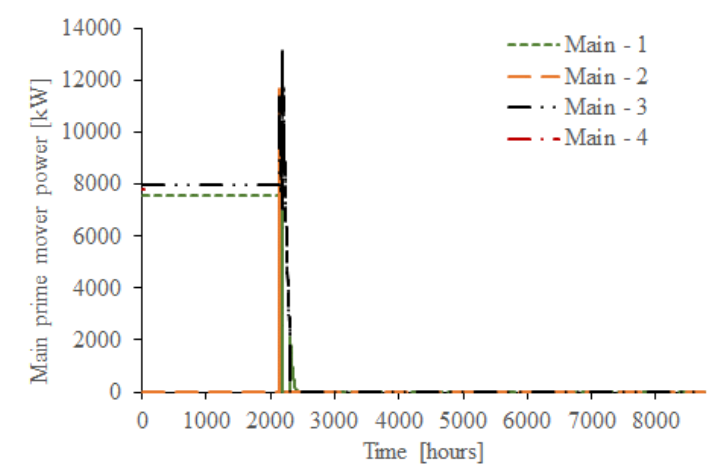

Fig. 19. Producing levels of the prime movers for propulsion system (the same results for IFO 380 and MDO), with respect to annual duration curve of effective propulsion load, where a typical operation day has $\ell_{\text {route }}=175$ n.miles, $V=22$ knots, $n_{A E S}=0.92, n_{\text {classic }}=0.97 \&$ 0 calls at intermediate ports.

It is noted that electric power SMC is unaffected by the use of fuel oil kind, as the last one is connected only with the propulsion system. The difference between the propulsion SMC using IFO 380 and the respective one using MDO is proportional with respect to the fuel oil costs. Because of the last one the prime movers producing levels are not modified using IFO 380 or MDO.

\subsection{Problem type " 1 " - Sensitivity analysis}

The conclusions for change of fuel oil kind from MDO to IFO 380 for propulsion system and for the change of fuel oil cost are the same ones with $\S 4.3$.

Beyond the fuel oil kind and cost crucial parameters for the dispatch comparison are the daily route characteristics, such as maximum trip speed, route length and the calls at intermediate ports. More specifically, in case of the propulsion system using IFO 380 the annual reduction cost in m.u., the total operation cost in m.u. and the annual percentage reduction cost with respect to the maximum trip speed are presented in Fig. 20, 21, 22 respectively for calls at intermediate ports from 0 to 4 and constant route length of $175 \mathrm{n}$. miles. The annual reduction cost varies from 5.34 to 210 m.u., while the respective percentage reduction cost comes to $0.00587 \%$, which is practically null. It is noted that if the maximum trip speed is increased, the annual operation cost is increased, but as the calls at intermediate ports is increased, the respective change is more limited, because during the arrival / departure sub-period at the ports ship speed is smaller than the maximum trip one. The annual reduction cost and the percentage one are presented strong no-linear behavior, i.e. at 21.75 knots, which is owed to the technical characteristics of the prime movers.

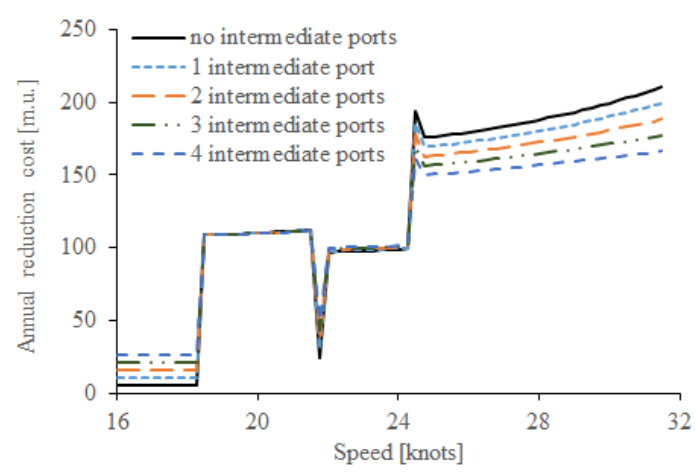

Fig. 20. Annual reduction cost for propulsion system using IFO 380 with respect to maximum trip speed with $\ell_{\text {route }}=175$ n.miles, $n_{A E S}=0.92, n_{\text {classic }}=0.97$, for $0 \ldots 4$ calls at intermediate ports.

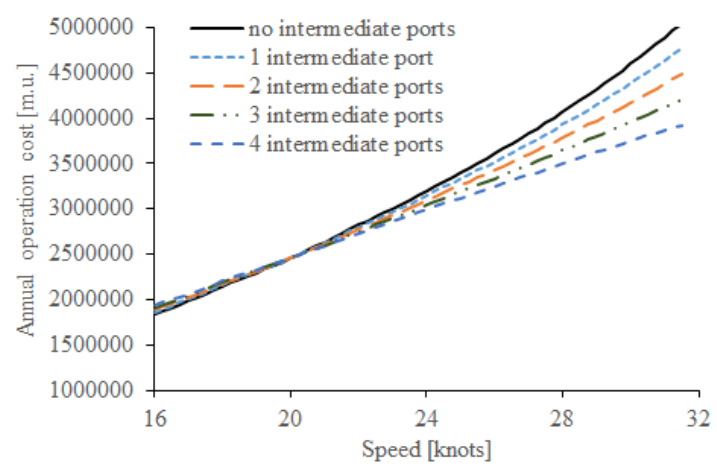

Fig. 21. Annual operation cost for propulsion system using IFO 380 with respect to maximum trip speed with $\ell_{\text {route }}=175$ n.miles, $n_{A E S}=0.92, n_{\text {classic }}=0.97$, for $0 \ldots 4$ calls at intermediate ports.

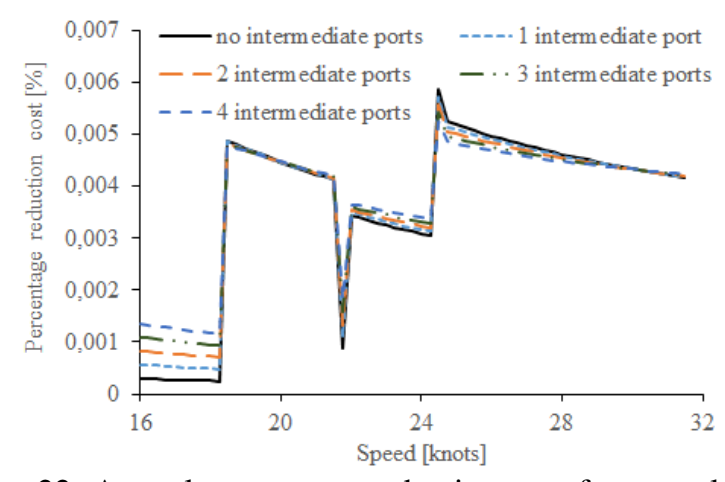

Fig. 22. Annual percentage reduction cost for propulsion system using IFO 380 with respect to maximum trip speed with $\ell_{\text {route }}=175$ n.miles, $n_{A E S}=0.92, n_{\text {classic }}=0.97$, for $0 \ldots 4$ calls at intermediate ports.

In case of the propulsion system using MDO the conclusions are similar to the previous ones, as the annual percentage reduction cost is almost identical to the IFO 380 ones, as it can be seen in Fig. 23. The annual reduction cost varies from 5.34 to 297 m.u., while the respective percentage reduction cost comes to $0.0062 \%$. 


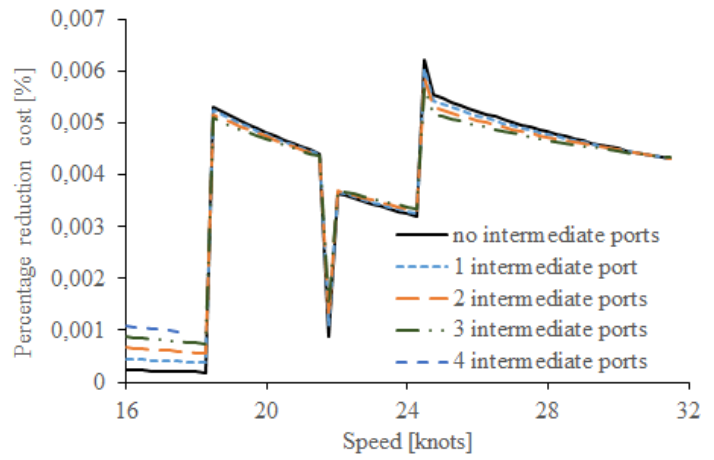

Fig. 23. Annual percentage reduction cost for propulsion system using MDO with respect to maximum trip speed with $\ell_{\text {route }}=175$ n.miles, $n_{A E S}=0.92, n_{\text {classic }}=0.97$, for $0 \ldots 4$ calls at intermediate ports.

Alternatively, the effects of the route length for constant maximum trip speed is examined. In case of the propulsion system using IFO 380 the annual reduction cost in m.u., the total operation cost in m.u. and the annual percentage reduction cost with respect to the route distance are presented in Fig. 24, 25,26 respectively for calls at intermediate ports from 0 to 4 and constant maximum trip speed of 22 knots. The annual reduction cost varies from 28.41 to 167.73 m.u. quite linearly. The respective percentage reduction cost comes to $0.00391 \%$.

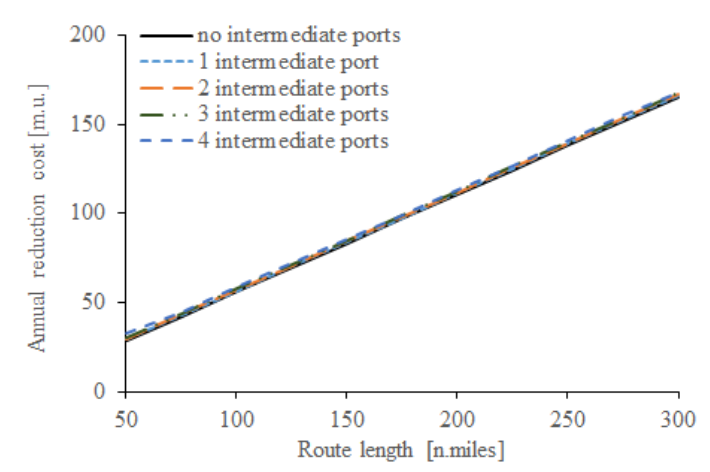

Fig. 24. Annual reduction cost for propulsion system using IFO 380 with respect to route length with $V=22$ knots, $\quad n_{A E S}=0.92, \quad n_{\text {classic }}=0.97$, for $0 \ldots 4$ calls at intermediate ports.

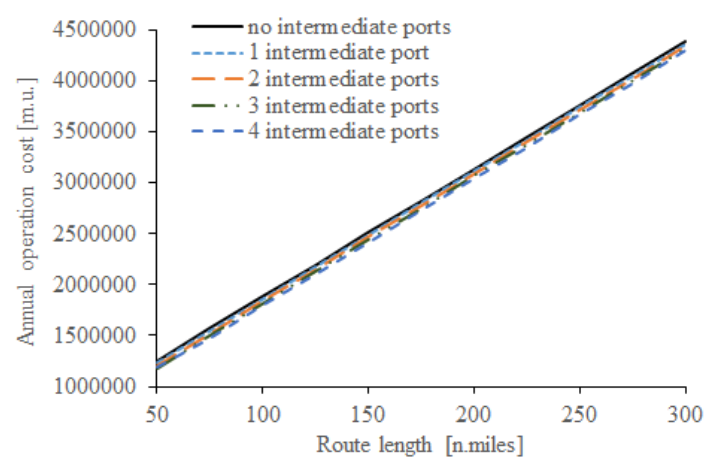

Fig. 25. Annual operation cost for propulsion system using IFO 380 with respect to route length with $V=22$ knots, $\quad n_{A E S}=0.92, \quad n_{\text {classic }}=0.97$, for $0 \ldots 4$ calls at intermediate ports.

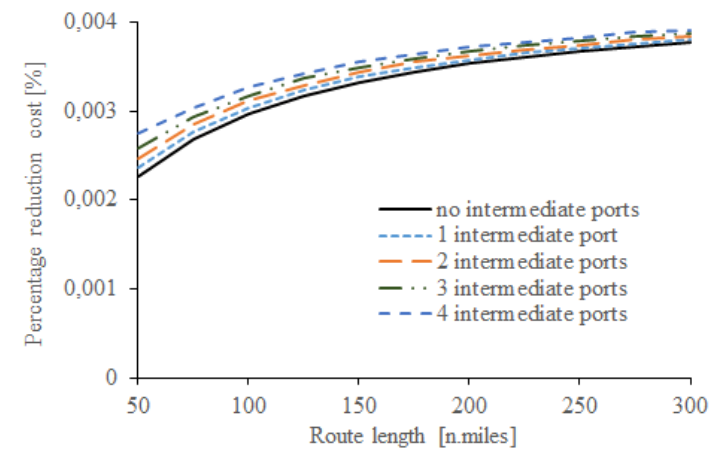

Fig. 26. Annual percentage reduction cost for propulsion system using IFO 380 with respect to route length with $V=22$ knots, $n_{A E S}=0.92, n_{\text {classic }}=0.97$, for $0 \ldots 4$ calls at intermediate ports.

But it is obvious that if the route length is increased, the percentage reduction cost is increased, as well as if the calls at intermediate ports is increased, the respective increment is bigger. In case of the propulsion system using MDO the annual percentage reduction cost is similar to the IFO 380 ones, but it is expanded to a narrower area, as it can be seen in Fig. 27. The annual reduction cost varies from 38.05 to 233 m.u., while the respective percentage reduction cost comes to $0.00397 \%$, which is practically null.

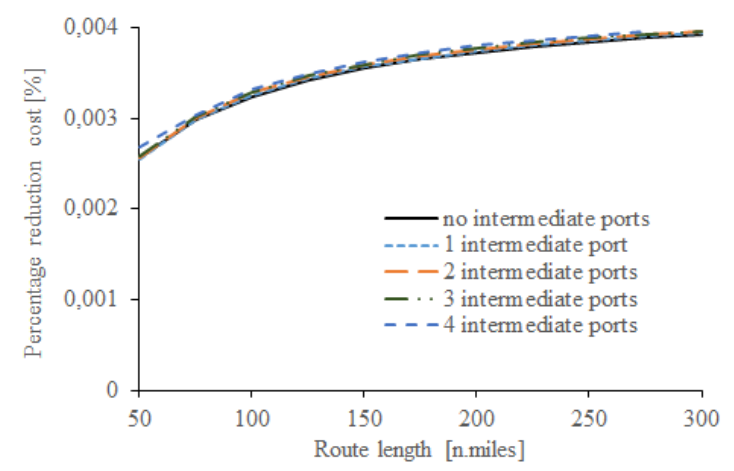

Fig. 27. Annual percentage reduction cost for propulsion system using MDO with respect to route length with $V=22$ knots, $n_{A E S}=0.92, n_{\text {classic }}=0.97$, for $0 \ldots 4$ calls at intermediate ports.

\subsection{Problem type "2" - Basic Scenario}

Here, the optimum economic dispatch for AES and the proportional one for conventional ship configuration are compared in a specific route (basic scenario), where from the annual duration effective propulsion load curve in Fig. 15 and the respective electric service load in Fig. 16 the total electric load is calculated by eq. (13) and the respective summation, as it can be seen in Fig. 28. Next, the optimal economic dispatch is carried out in unified power system in both cases (low speed diesel engines use IFO 380 or MDO) and the respective SMCs are presented in Fig. 29, as well as the 
generating level of the high speed diesel engines and of the low speed ones are also shown in Fig. 30 and 31 for IFO 380 \& MDO, in Fig. 32 and 33 for MDO only respectively. The SMC variations are big in the area of the steep load changes, i.e. $2200 \mathrm{~h}$, while beyond $3900 \mathrm{~h}$ both SMCs are identical in Fig. 29, because only high speed diesel generators operate. The last one is obvious from the observation and the respective comparison of Fig. 30 with 32,31 with 33, where beyond time point $3900 \mathrm{~h}$ approximately no low speed diesel generator operate. It is noted that the generating levels of the generators have been differentiated significantly in cases of using different kind of fuel oil, because, if the low speed diesel generators (the modified main machines prime movers) use MDO, they will produce power only for high total electric load. In case of using IFO 380 for low speed diesel generators the cost reduction for optimal dispatch is $-14,513.125$ m.u., otherwise $-0.514 \%$. In case of using MDO the respective results are $-84,574,453$ m.u., otherwise $2.278 \%$ respectively. In both cases the basic scenario for AES is not economic viable. That's why the hourly reduction cost and the respective percentage one are examined in Fig. 34 and 35.

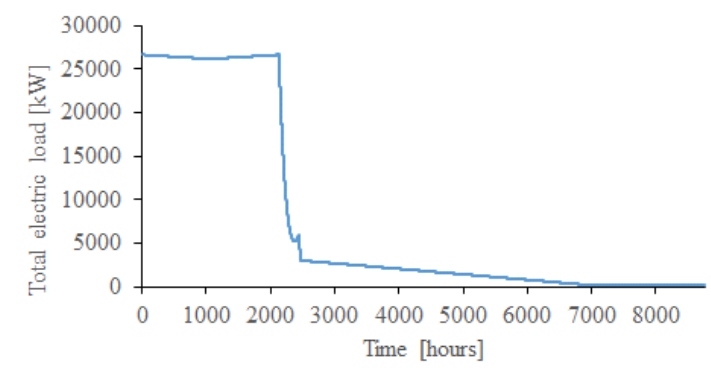

Fig. 28. Annual total electric load curve with respect to annual duration curve of effective propulsion load, where a typical operation day has $\ell_{\text {route }}=175$ n.miles, $V=22$ knots, $n_{A E S}=0.92, n_{\text {classic }}=0.97 \& 0$ calls at intermediate ports.

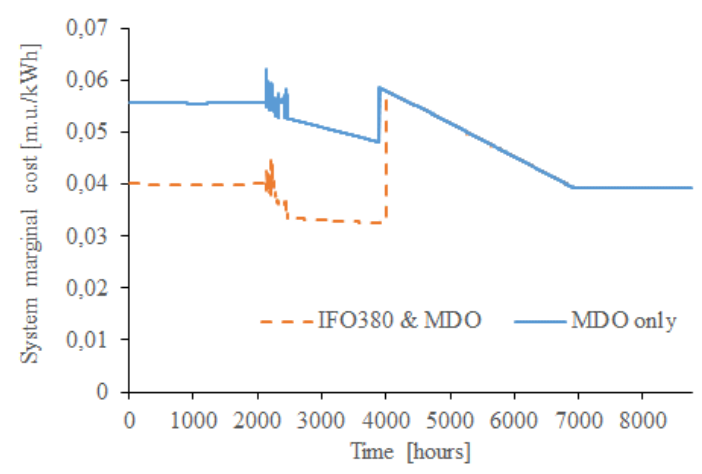

Fig. 29. System marginal cost curve for AES using IFO $380 \&$ MDO and MDO only, with respect to annual duration curve of effective propulsion load, where a typical operation day has $\ell_{\text {route }}=175$ n.miles, $V=22$ knots, $n_{A E S}=0.92, n_{\text {classic }}=0.97 \& 0$ calls at intermediate ports.

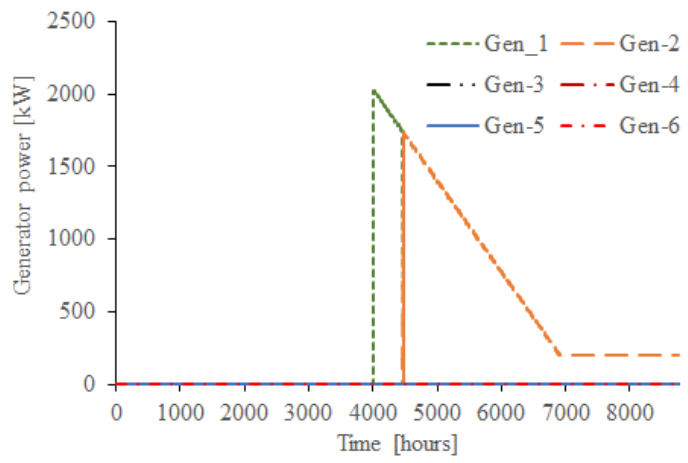

Fig. 30. Generating levels of the high speed diesel engines for AES burning IFO 380 \& MDO with respect to annual duration curve of effective propulsion load, where a typical operation day has $\ell_{\text {route }}=175$ n.miles, $V=22$ knots, $n_{A E S}=0.92, \quad n_{\text {classic }}=0.97 \& 0$ calls at intermediate ports.

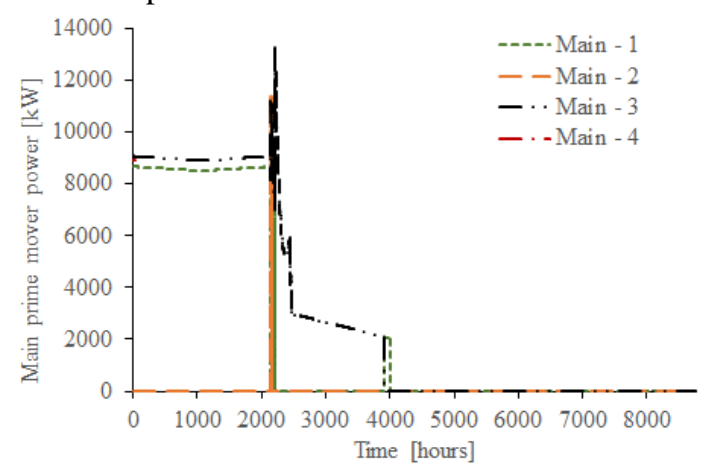

Fig. 31. Generating levels of the low speed diesel engines for AES burning IFO 380 \& MDO with respect to annual duration curve of effective propulsion load, where a typical operation day has $\ell_{\text {route }}=175$ n.miles, $V=22$ knots, $n_{\text {AES }}=0.92, n_{\text {classic }}=0.97 \& 0$ calls at intermediate ports.

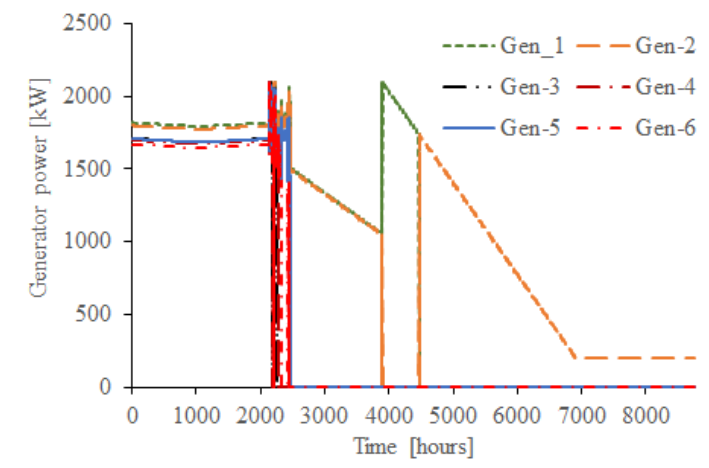

Fig. 32. Generating levels of the high speed diesel engines for AES burning MDO only with respect to annual duration curve of effective propulsion load, where a typical operation day has $\ell_{\text {route }}=175$ n.miles, $V=22$ knots, $n_{A E S}=0.92, n_{\text {classic }}=0.97 \& 0$ calls at intermediate ports.

In Fig. 34 and 35 the positive results are presented for electric load of $10 \mathrm{MW}$ or smaller. It is also obvious that there is significant improvement of percentage reduction cost and of hourly reduction cost in case of using IFO 380 by low speed diesel generators, but it is not enough to success the economic viability of AES for the basic scenario. 


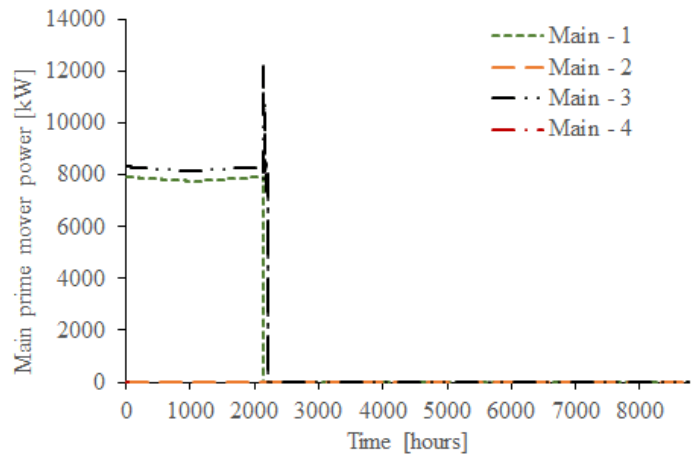

Fig. 33. Generating levels of the low speed diesel engines for AES burning MDO only with respect to annual duration curve of effective propulsion load, where a typical operation day has $\ell_{\text {route }}=175$ n.miles, $V=22$ knots, $n_{A E S}=0.92, n_{\text {classic }}=0.97 \& 0$ intermediate ports.

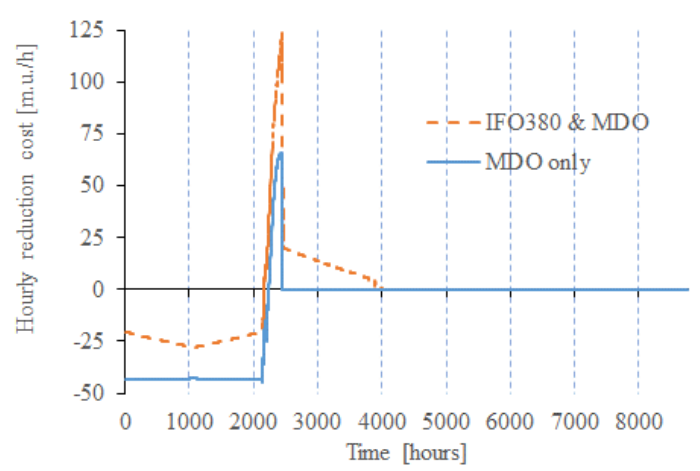

Fig. 34. Hourly reduction cost for AES burning IFO 380 $\&$ MDO and MDO only with respect to annual duration curve of effective propulsion load, where a typical operation day has $\ell_{\text {route }}=175$ n.miles, $V=22$ knots, $n_{A E S}=0.92, n_{\text {classic }}=0.97 \& 0$ calls at intermediate ports.

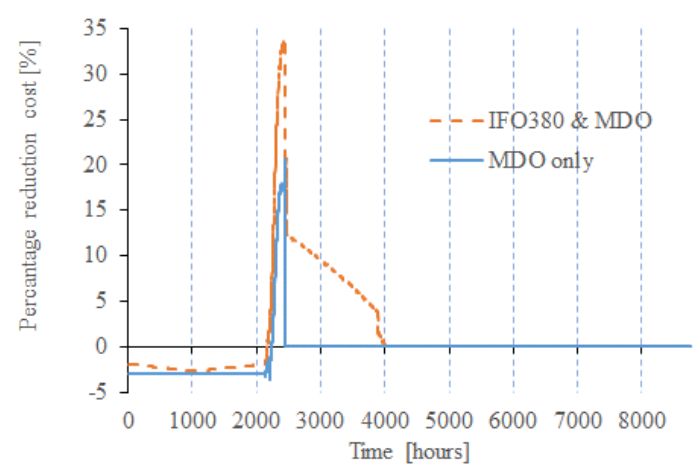

Fig. 35. Percentage hourly reduction cost for AES burning IFO 380 \& MDO and MDO only with respect to annual duration curve of effective propulsion load, where an typical operation day has $\ell_{\text {route }}=175$ n.miles, $V=22$ knots, $n_{A E S}=0.92, n_{\text {classic }}=0.97 \& 0$ calls at intermediate ports.

\subsection{Problem type "2" - Sensitivity analysis}

Here, the conditions for economic viability of AES with economic dispatch in comparison to classic configuration ship with proportional dispatch are investigated.

It is obvious from Fig. 34 and 35 that the change of fuel oil kind from MDO to IFO 380 improves significantly the reduction cost. Additionally, in case of use IFO $380 \&$ MDO the ratio between the MDO cost and IFO 380 one, influences the percentage reduction cost, where the ratio increment improves the respective percentage reduction cost from $-3.5 \%$ to $7.1 \%$ for no calls at intermediate ports, as it can be seen in Fig. 36. The neutral situation happens for $146 \%$ ratio approximately, which is improved as the calls at intermediate ports increases ( $124 \%$ for 4 calls at intermediate ports). It is noted that the ratio value is $142 \%$ approximately for the basic scenario [27], which is slightly smaller than $146 \%$ and justifies that the reduction cost is negative.

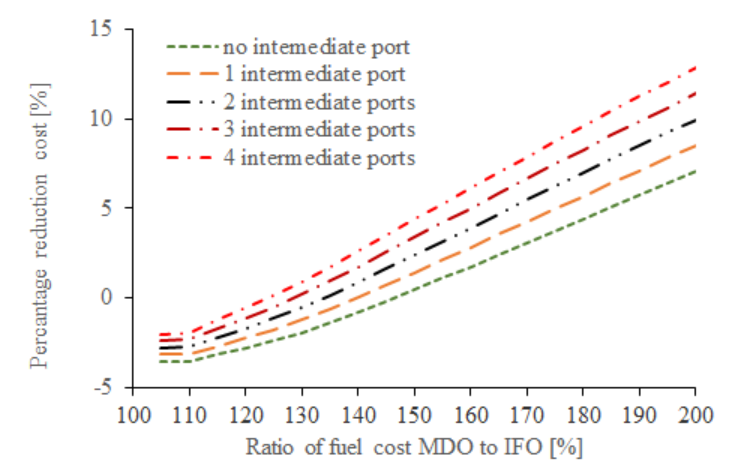

Fig. 36. Percentage reduction cost using Lagrange dispatch in AES instead of proportional dispatch in similar classic ship burning different fuel oil (low-speed diesel engines: IFO 380, high speed ones: MDO) with respect to ratio of fuel cost MDO to IFO 380, where a typical operation day has $\ell_{\text {route }}=175 \mathrm{n}$. miles, $V=22$ knots, $n_{A E S}=0.92, n_{\text {classic }}=0.97 \& 0, \ldots, 4$ calls at intermediate ports.

Next, the AES propulsion chain factor $n_{A E S}$ is examined, as its typical values are from 0.86 to 0.92, while in future technical improvements can result in values to 0.96 . The annual operation cost and the respective percentage reduction cost are presented with respect to the AES propulsion chain factor $n_{A E S}=[0.86,0.97]$ and the maximum ship speed $V=[16,31$ knots] for constant route length in Fig. 37 and 38 using IFO 380 \& MDO, in Fig. 39 and 40 using MDO only.

It is obvious that the use of IFO $380 \& \mathrm{MDO}$ gives lower operation cost than the respective ones using MDO only. The percentage reduction operation cost variation for the use of IFO $380 \&$ $\mathrm{MDO}$ is bigger from $-12.06 \%$ to $5.71 \%$ than the respective one for MDO use from $-9.69 \%$ to $3.50 \%$. However, the area with advantageous results for AES is much bigger in first case, especially for maximum ship speed smaller than 20 knots and for AES propulsion chain factor bigger than 0.91 . 


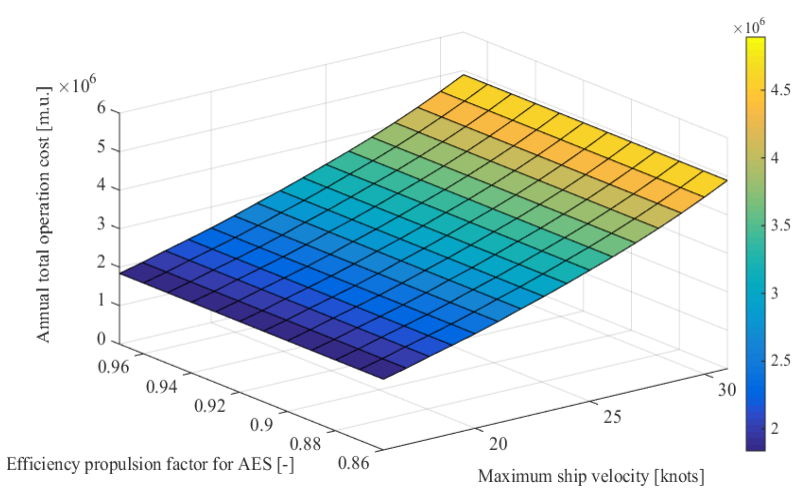

Fig. 37. Annual total operation cost using Lagrange dispatch in AES instead of proportional dispatch in similar classic ship burning different fuel oil (low speed diesel engines: IFO 380, high speed diesel engines: MDO) with respect to $n_{A E S}$ and to maximum ship speed with $n_{\text {classic }}=0.97, \quad \ell_{\text {route }}=175$ n.miles, 0 calls at intermediate ports.

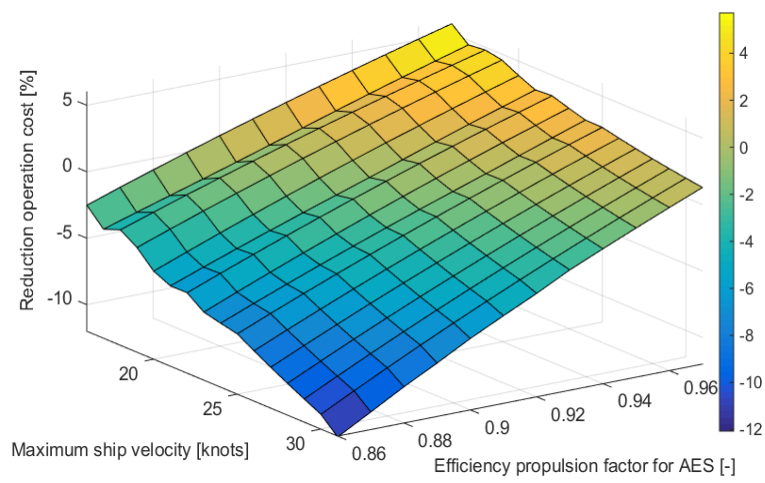

Fig. 38. Percentage reduction operation cost using Lagrange dispatch in AES instead of proportional dispatch in similar classic ship burning different fuel oil (low speed diesel engines: IFO 380, high speed diesel engines: MDO) with respect to $n_{A E S}$ and to maximum ship speed with $n_{\text {classic }}=0.97, \ell_{\text {route }}=175$ n.miles, 0 calls at intermediate ports.

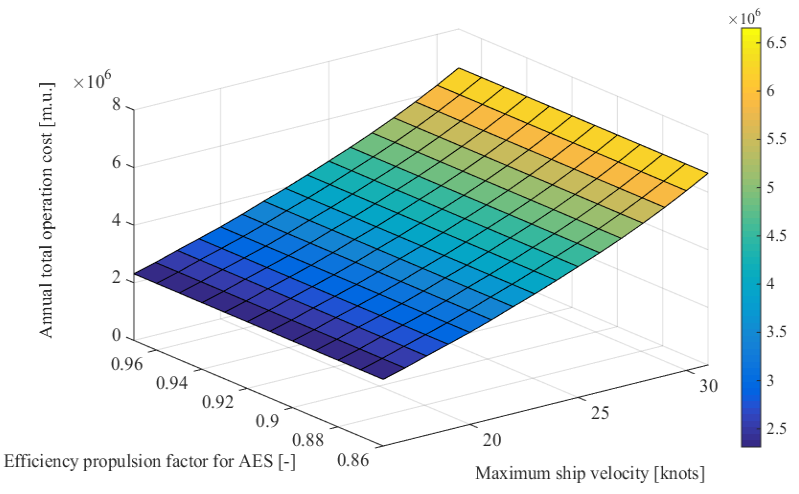

Fig. 39. Annual total operation cost using Lagrange dispatch in AES instead of proportional dispatch in similar classic ship burning same fuel oil for all engines (MDO) with respect to $n_{A E S}$ and to maximum ship speed with $n_{\text {classic }}=0.97, \quad \ell_{\text {route }}=175$ n.miles, 0 calls at intermediate ports.

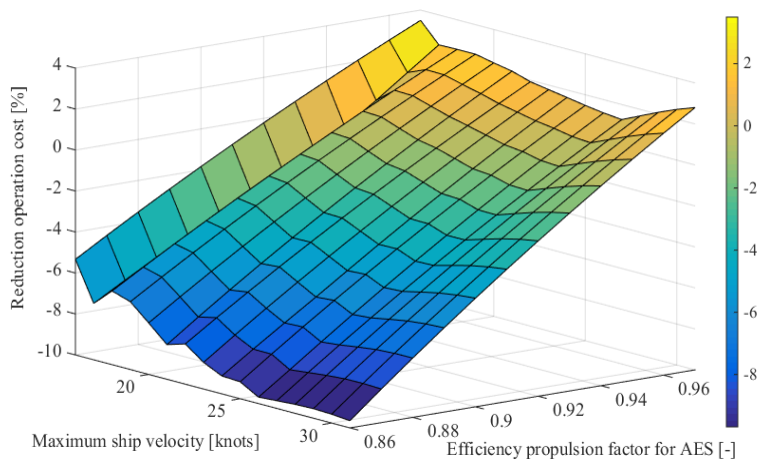

Fig. 40. Percentage reduction operation cost using Lagrange dispatch in AES instead of proportional dispatch in similar classic ship burning same fuel oil for all engines (MDO) with respect to $n_{A E S}$ and to maximum ship speed with $n_{\text {classic }}=0.97, \ell_{\text {route }}=175$ n.miles, 0 calls at intermediate ports.

If the calls at intermediate ports increase, the respective advantageous results for AES will be expanded. In case of using IFO 380 \& MDO with 4 calls at intermediate ports the percentage reduction operation cost varies from $-6.63 \%$ to $9.19 \%$ (see Fig. 41), being positive for maximum ship speed smaller than 19 knots for every AES propulsion chain factor bigger than 0.86 , as well as for maximum ship speed smaller than 30 knots for AES propulsion chain factor bigger than 0.92 . In case of MDO only the respective improvement is more limited (see Fig. 42). Indicatively for 4 calls at intermediate ports the percentage reduction operation cost varies from $-7.85 \%$ to $6.63 \%$, being positive for maximum ship speed smaller than 22 knots for every AES propulsion chain factor bigger than 0.93 .

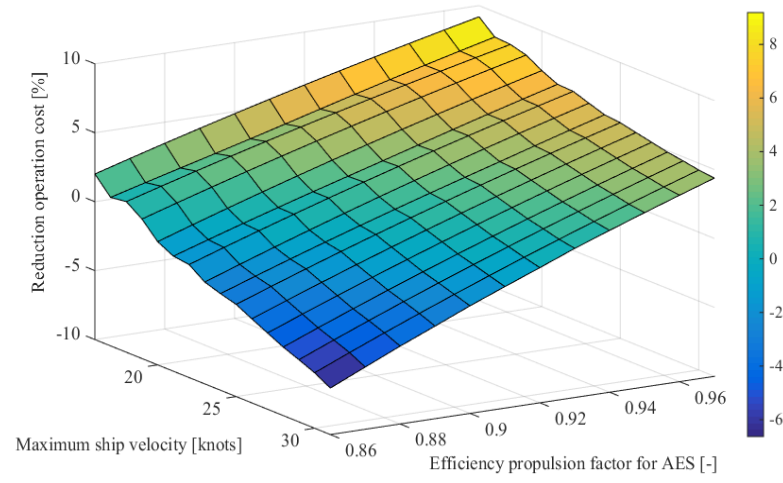

Fig. 41. Percentage reduction operation cost using Lagrange dispatch in AES instead of proportional dispatch in similar classic ship burning different fuel oil (low speed diesel engines: IFO 380, high speed diesel engines: MDO) with respect to $n_{A E S}$ and to maximum ship speed with $n_{\text {classic }}=0.97, \ell_{\text {route }}=175$ n.miles, 4 calls at intermediate ports. 


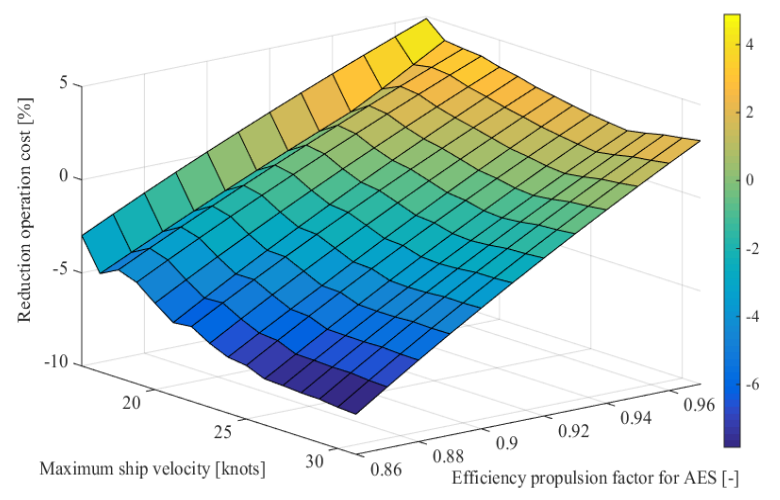

Fig. 42. Percentage reduction operation cost using Lagrange dispatch in AES instead of proportional dispatch in similar classic ship burning same fuel oil for all engines (MDO) with respect to $n_{A E S}$ and to maximum ship speed with $n_{\text {classic }}=0.97, \ell_{\text {route }}=175$ n.miles, 4 calls at intermediate ports.

Alternatively, the annual operation cost and the respective percentage reduction cost are presented with respect to the AES propulsion chain factor $n_{A E S}$ $=[0.86,0.97]$ and the route length $\ell_{\text {route }}=[50,300 \mathrm{n}$. miles] with constant maximum ship speed in Fig. 43 and 44 using IFO $380 \&$ MDO, in Fig. 45 and 46 using MDO only. The use of IFO $380 \&$ MDO gives lower operation cost than the respective ones using MDO only. The percentage reduction operation cost for the use of IFO $380 \&$ MDO varies from $-7.46 \%$ to $4.84 \%$, while the respective one for MDO use from $-8.88 \%$ to $1.96 \%$. It is obvious that the area with advantageous results for AES is much bigger in first case, especially for length route smaller than 150 nautical miles and for AES propulsion chain factor bigger than 0.91 .

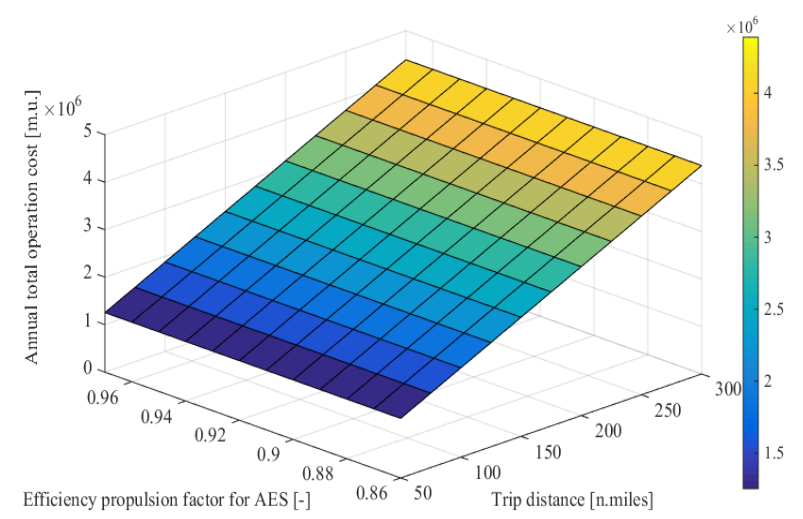

Fig. 43. Annual total operation cost using Lagrange dispatch in AES instead of proportional dispatch in similar classic ship burning different fuel oil (low speed diesel engines: IFO 380, high speed diesel engines: MDO) with respect to $n_{A E S}$ and to route length with $n_{\text {classic }}=0.97, V=22$ knots, 0 calls at intermediate ports.

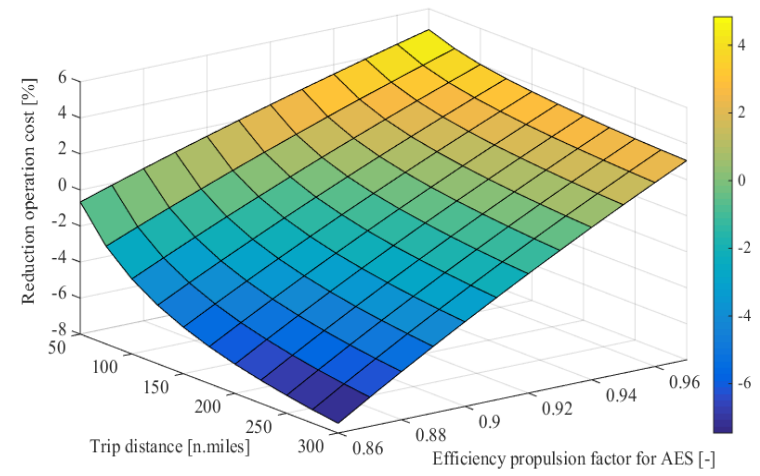

Fig. 44. Percentage reduction operation cost using Lagrange dispatch in AES instead of proportional dispatch in similar classic ship burning different fuel oil (low speed diesel engines: IFO 380, high speed diesel engines: MDO) with respect to $n_{A E S}$ and to route length with $n_{\text {classic }}=0.97, V=22$ knots, 0 calls at intermediate ports.

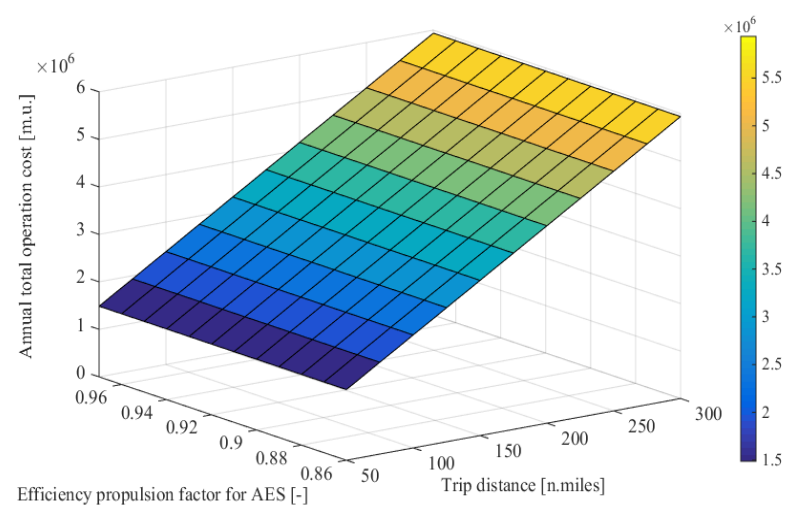

Fig. 45. Annual total operation cost using Lagrange dispatch in AES instead of proportional dispatch in similar classic ship burning same fuel oil for all engines (MDO) with respect to $n_{A E S}$ and to route length with $n_{\text {classic }}=0.97, V=22$ knots, 0 calls at intermediate ports.

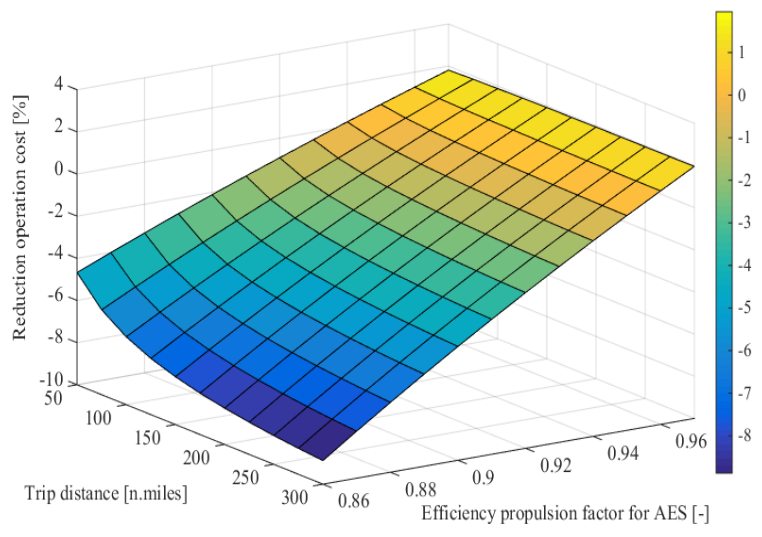

Fig. 46. Percentage reduction operation cost using Lagrange dispatch in AES instead of proportional dispatch in similar classic ship burning same fuel oil for all engines (MDO) with respect to $n_{A E S}$ and to route length with $n_{\text {classic }}=0.97, V=22$ knots, 0 calls at intermediate ports. 
If the calls at intermediate ports increases, the respective advantageous results for AES will be expanded. In case of using IFO $380 \&$ MDO with 4 calls at intermediate ports the percentage reduction operation cost varies from $-4.86 \%$ to $11.86 \%$ (see Fig. 47), being positive for route length smaller than 150 nautical miles for every AES propulsion chain factor bigger than 0.86 , as well as for route length smaller than 300 nautical miles for AES propulsion chain factor bigger than 0.91. In case of MDO, only the respective improvement is more limited (see Fig. 48). Indicatively for 4 calls at intermediate ports the percentage reduction operation cost varies from $7.65 \%$ to $4.85 \%$, being positive for route length smaller than 125 nautical miles for every AES propulsion chain factor bigger than 0.92 .

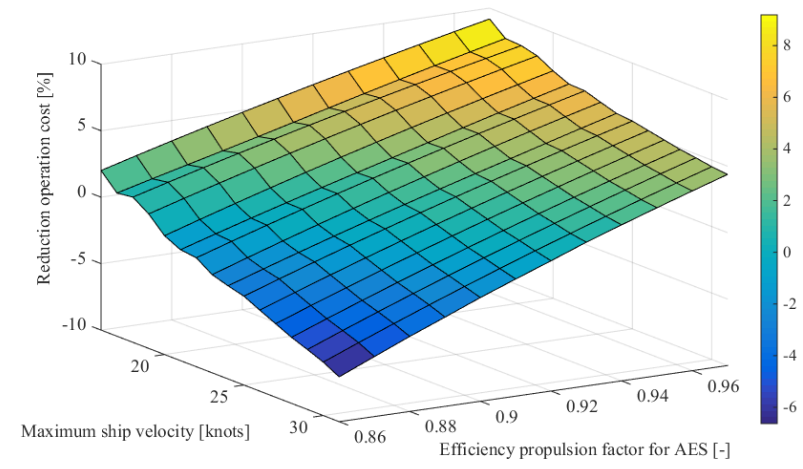

Fig. 47. Percentage reduction operation cost using Lagrange dispatch in AES instead of proportional dispatch in similar classic ship burning different fuel oil (low speed diesel engines: IFO 380, high speed diesel engines: MDO) with respect to $n_{A E S}$ and to route length with $n_{\text {classic }}=0.97, V=22$ knots, 4 calls at intermediate ports.

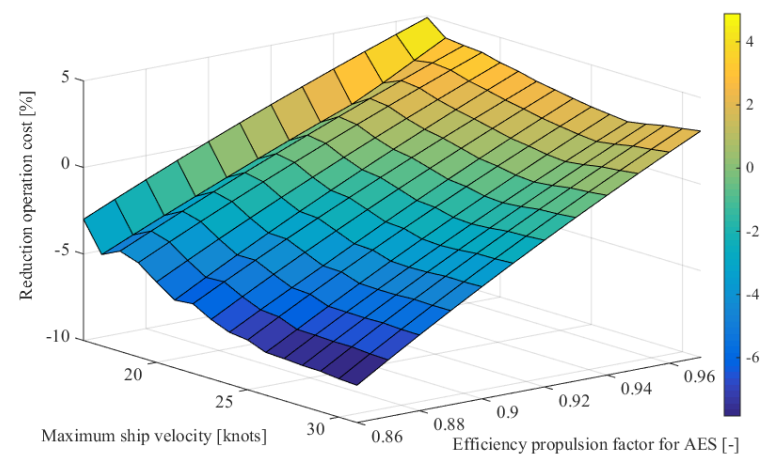

Fig. 48. Percentage reduction operation cost using Lagrange dispatch in AES instead of proportional dispatch in similar classic ship burning same fuel oil for all engines (MDO) with respect to $n_{A E S}$ and to route length with $n_{\text {classic }}=0.97, \quad V=22$ knots, 4 calls at intermediate ports.

\section{Conclusions}

In this paper the optimal dispatch for ship power system is presented based on Lagrange method and two problems for the financial comparison between optimum economic dispatch and proportional one for a conventional ship (problem type "1") or optimum economic dispatch for AES and proportional one for the respective conventional ship (problem type "2") are examined with two methodologies.

In case of the methodology "A" the optimal economic dispatch for conventional ship or AES and the proportional dispatch for conventional ship are carried out for different values of electric service load $P_{\text {servel } e l}$ and of effective propulsion load $P_{\text {prop. }}$. The respective minimum, maximum and indicative mean value operation cost are calculated either separately for electric power system and propulsion system for problem type "1" or together for each combination $\left(P_{\text {servel }}, P_{\text {prop }}\right)$ for problem type "2", under the condition that the probability density function for each load is uniform.

In problem type " 1 " the infinitesimal improvement by economic power dispatch application instead of proportional one is due to the almost identical economic and technical characteristics of prime movers for each system, which lead on to similar results between two dispatch kinds. The change of fuel oil kind from marine diesel oil (MDO) to intermediate fuel oil (IFO) for propulsion system does not modify the percentage reduction cost in all propulsion loads, but only the monetary unit cost, where the use of IFO is more desirable. However, there is the problem if the IFO use is legal according to vessel route. Furthermore, the change of fuel oil cost does not modify the percentage reduction cost, because the electric power system and propulsion system operates independently and the fuel cost functions of generators / prime movers change proportionally.

In problem type " 2 " AES using optimal power dispatch has a significant advantage against conventional one for medium to high service electric load and medium to low effective propulsion load, because the main prime movers, which were used for propulsion system initially, operate as generators supplying electric service load in a more inexpensive way. This advantage is limited if both low and high speed diesel engines use MDO for environmental / legislation reasons. This happens, because the main prime movers, which were used for propulsion system initially, do not use the cheaper IFO 380, but MDO, which means that their inexpensive operation is based on the slightly better efficiency than the classical high speed diesel electric generators. Additionally, the change of fuel oil cost does not modify the percentage reduction cost in case of only use of 
MDO, because the fuel cost functions of generators / prime movers change proportionally. On the contrary in case of use IFO $380 \&$ MDO the ratio between the MDO cost and IFO 380 one influences the percentage reduction cost, where the ratio increment improves the respective mean operation cost. Furthermore, the AES propulsion chain factor plays the most significant role, as its increase leads on to the expansion of the area, where AES Lagrange dispatch is superior to the proportional dispatch of conventional ship, in both cases of fuel use.

In case of the methodology " $\mathrm{B}$ " both problem types are carried out for a specific ship route taking into account the respective chronological load curve of electric service load and of effective propulsion load during operation and no operation of the ship. The annual operation cost is estimated and compared.

In problem type " 1 " the results are quite similar again, as it was for the respective results of methodology "A". In both cases of fuel oil kind the improvement is practically null (percentage reduction cost $0.0034 \%$ using IFO $380 \&$ MDO, $0.0037 \%$ using MDO only). If the maximum trip speed is increased, the annual operation cost is also increased, but the reduction cost changes nolinearly. As the calls at intermediate ports is increased, the respective change is more limited, because during the arrival / departure sub-period at the ports ship speed is smaller than the maximum trip one. If the route length is increased with constant maximum ship speed, the percentage reduction cost is increased, as well as, if the calls at intermediate ports is increased too, the respective increment is bigger.

In problem type " 2 " there is significant improvement of percentage reduction cost and of hourly reduction cost in case of using IFO 380 by low speed diesel generators, but it is not enough to success the economic viability of AES for the basic scenario. The change of fuel oil kind from MDO to IFO 380 improves significantly the reduction cost. Additionally, in case of use IFO 380 \& MDO the ratio between the MDO cost and IFO 380 one influences the percentage reduction cost, where the ratio increment improves the respective percentage reduction cost. Similarly, the percentage reduction operation cost is improved as the AES propulsion chain factor is increased, the maximum ship speed is decreased, the route length is decreased and the calls at intermediate ports is decreased. The advantageous results are more obvious if the use of IFO 380 is permitted.
References:

[1] IMO, Resolution MEPC.213 (63): 2012 Guidelines for the development of a Ship Energy Efficiency Management Plan (SEEMP), IMO publications, 2012.

[2] H.K. Woud, D. Stapersma, Design of propulsion and electric power generation systems, IMAREST publications, 2002.

[3] ABB, System project guide for passenger vessels, ABB publications, 2011.

[4] P. Michalopoulos, G. J. Tsekouras, J. M. Prousalidis, F.D. Kanellos, "Comparison of ship power system from an Optimal Economic Operation Point of View," IEEE Electric Ship Technologies Symposium (IEEE ESTS '15), Washington DC USA, June 22-24, 2015.

[5] J. M. Prousalidis, G. J. Tsekouras, F.D. Kanellos, "New challenges emerged from the development of more efficient electric energy generation units," IEEE Electric Ship Technologies Symposium (IEEE ESTS '11), Westin Alexandria, Alexandria, Virginia, USA, April 10-13, 2011.

[6] L. Hanyu, M. Longhua, "Construction of Integrated Smart Power System for Future Ship" International Conference on Power System Technology, China, Oct. 24-28, 2010.

[7] J.A. Momoh, Electric power system applications of optimization, Marcen Dekker Inc., 2001.

[8] F. Saccomano, Electric power systems, analysis and control, Wiley-IEEE Press, 2003.

[9] F.D Kanellos, J. M. Prousalidis, G. J. Tsekouras, "Control system for fuel consumption minimization-gas emission limitation of full electric propulsion ship power systems," Proceedings of the Institution of Mechanical Engineers, Part M: Journal of Engineering for the Maritime Environment, vol. 228, no. 1, 2014, pp. 17-28.

[10] F.D.Kanellos, G. J. Tsekouras, N.D. Hatziargyriou, "Optimal demand-side management and power generation scheduling in all-electric ship," IEEE Transactions on Sustainable Energy, vol. 5, no. 4, 2014, pp. 1166-1175.

[11] J. S. Thongam, M. Tarbouchi, A. F. Okou, D. Bouchard, R. Beguenane, "All-Electric Ships A Review of the Present State of the Art," International Conference and Exhibition on Ecological Vehicles and Renewable Energies, Monte Carlo, Monaco, March 27-30, 2013.

[12] P. Michalopoulos, F. Kanellos, G. J. Tsekouras, J. Prousalidis: "A Method for Optimal Operation of Complex Ship Power Systems 
Employing Shaft Electric Machines", IEEE Transactions on Transportation Electrification, vol. 2, no. 4, 2016, pp. 547-556.

[13] G. J. Tsekouras, F.D. Kanellos, J.M. Prousalidis, "Simplified method for the assessment of ship electric power systems operation cost reduction from energy storage and renewable energy sources integration," IET Electrical Systems in Transportation, vol. 5, no 2, 2015, pp. 61-69.

[14] G. J. Tsekouras, F. D. Kanellos, "Optimal operation of ship electrical power system with energy storage system and photovoltaics: Analysis and application," WSEAS Transactions on Power Systems, vol. 8, no. 4, 2013, pp.145-155.

[15] K.-J. Lee, D. Shin, D.-W. Yoo, H.-K. Choi, H.J. Kim, "Hybrid photovoltaic/diesel green ship operating in standalone and grid-connected mode - Experimental investigation," Energy, vol. 49, 2012, pp. 475-483.

[16] Z. Li, Y. Xu, S. Fang, Y. Wang, X. Zheng, "Multiobjective Coordinated Energy Dispatch and Voyage Scheduling for a Multienergy Ship Microgrid," IEEE Transactions on Industry Applications, vol. 56, no. 2, 2020, pp. 989-999.

[17] M. Banaei, M. Rafiei, J. Boudjadar, M. Khooban, "A Comparative Analysis of Optimal Operation Scenarios in Hybrid Emission-Free Ferry Ships," IEEE Transactions on Transportation Electrification, vol. 6, no. 1, 2020, pp. 318-333.

[18] J. Hou, J. Sun, HF. Hofmann, "Mitigating power fluctuation in electric ship propulsion with hybrid energy storage system: design and analysis," IEEE Journal of Oceanic Engineering, vol. 43, no. 1, 2018, pp.93-107.

[19] S. Fang, B. Gou, Y. Wang, Y. Xu, C. Shang, H. Wang, "Optimal Hierarchical Management of Shipboard Multibattery Energy Storage System Using a Data-Driven Degradation Model," IEEE Transactions on Transportation Electrification, vol. 5, no. 4, 2019, pp. 13061318.

[20] Y. Huang, H. Lan, Y.-Y. Hong, S. Wen, S. Fang, "Joint voyage scheduling and economic dispatch for all-electric ships with virtual energy storage systems," Energy, Vol. 190, 2020, no. paper 116268, p. 9.

[21] G. Seenumani, Real-time Power Management of Hybrid Power Systems in All Electric Ship Applications, Ph.D. dissertation, University of Michigan, 2010.

[22] B. Zahedi, L. E. Norum, K. B. Lunvigsen, "Optimized efficiency of all electric ships by dc hybrid power systems," Journal of Power Sources, vol. 255, 2014, pp. 341-355.

[23] X. Feng, K. L. Butler-Purry, T. Zourntos, "Multi-agent system-based real-time load management for all-electric ship power systems in dc zone level," IEEE Transactions on Power Systems, Vol. 27, no. 4, 2012, pp. 1719-1728.

[24] A. Swider, E. Pedersen, "Data-Driven Methodology for the Analysis of Operational Profile and the Quantification of Electrical Power Variability on Marine Vessels," IEEE Transactions on Power Systems, vol. 34, no. 2, 2019, pp. 1598-1609.

[25] A. Swider, H. Langseth, E. Pedersen, "Application of data-driven models in the analysis of marine power systems," Applied Ocean Research, Vol. 92, 2019, no. paper 101934, p.11

[26] Chevron, Everything you need to know about marine fuels, Chevron publications, 2012.

[27] http://en.cpc.com.tw/MarineOilPrice.aspx

[28] Y. Wild, Determination of energy cost of electrical energy on board sea-going vessels, Ref.Nr. 2004/0036, Client: Thermo King Corp, 2015.

\section{Contribution of individual authors to the creation of a scientific article (ghostwriting policy)}

George J. Tsekouras carried out the conceptualization, the investigation, the methodology, the programming, the simulation, the visualization and the writing.

Fotios D. Kanellos carried out the conceptualization, the investigation, the methodology and the writing. Michalis Kontosoros carried out the programming, the simulation and the visualization.

\section{Creative Commons Attribution}

\section{License 4.0 (Attribution 4.0 \\ International , CC BY 4.0)}

This article is published under the terms of the Creative Commons Attribution License 4.0 https://creativecommons.org/licenses/by/4.0/deed.en US 